\title{
Renato FalCl JúNIOR
}

\section{Tratamento do cisto renal simples sintomático}

por aspiração percutânea e injeção permanente de álcool absoluto em sessão única

Tese apresentada ao Departamento de Cirurgia da Faculdade de Medicina da Universidade de São Paulo para obtenção do título de Doutor.

Área de concentração: Urologia Orientador: Prof. Dr. Antonio Marmo Lucon

São Paulo 
"A mente que se abre a uma nova idéia jamais voltará ao seu tamanho original"

(Albert Einstein) 
"O prazer no trabalho aperfeiçoa a

obra"

(Aristóteles) 


\section{Dedicatória}

A os meus pais Renato e Elizabeth, que nunca mediram esforços para me of erecer o melhor e a quem devo minha formação.

A L iane, que esteve presente com carinho, compreensão e companheirismo em todos os momentos.

A os meus irmãos, Ricardo, F elipe e $F$ abíola, pela amizade e apoio constantes. 


\section{Agradecimentos}

Ao Professor Doutor Antonio Marmo Lucon, chefe interino da Divisão de Clínica Urológica do Hospital das Clínicas da Faculdade de Medicina da Universidade de São Paulo, exemplo de liderança, ética e profissionalismo, orientador deste trabalho e da minha formação profissional, pelos ensinamentos, estímulos e contribuição notória na minha formação.

Ao Doutor José Luis Chambô, mestre e amigo, pelos ensinamentos constantes, estímulo, confiança no meu trabalho e aporte ímpar na minha formação médica e humana.

À Professora Doutora Luciana M. Oliveira Cerri, pela dedicação, estímulo e auxílio técnico.

Ao Professor Doutor Frederico Arnaldo de Queiroz e Silva, pela amizade, apoio e sugestões na redação deste trabalho.

Ao Doutor Fabio Baracat, pelo estímulo a este trabalho e apoio à minha carreira profissional.

Ao Doutor Eduardo Mazzucchi e ao Doutor Omar Reda ElHayek, pelas sugestões no presente estudo. 
Ao Doutor Renato Tuneyasu Yamada, pelo exemplo de disciplina e dedicação.

\begin{abstract}
À Doutora Paula Cristina Dias da Rocha, pelo auxílio técnico e contribuição relevante no seguimento dos pacientes.
\end{abstract}

Ao Doutor Alexandre Danilovic, residente brilhante, pela dedicação, presteza e auxílio na coleta de dados.

Ao Doutor Marcos Lucon, pelo aprendizado mútuo e estímulo à pesquisa.

Ao Doutor Bernardo Sobreiro, pelas sugestões na análise estatística e interpretação dos resultados.

Ao Doutor Hiroaki Shiina, MD, pelo auxílio na obtenção das referências publicadas em revistas japonesas.

Ao Doutor Affonso Celso Piovesan, pelas sugestões e suporte na elaboração da aula de qualificação.

Aos residentes de Urologia que, através da troca de conhecimentos, nos proporcionam aprendizado constante.

À Enfermeira Maria de Lourdes Possari e sua equipe, pela dedicação e auxílio nos cuidados com os pacientes.

À Sra. Elisa de Arruda Cruz da Silva, pelo auxílio nos trâmites da Pós-Graduação. 
À Sra. Eidi Baltrusis Gomes, pelo auxílio na pesquisa das referências bibliográficas.

À Sra. Mônica e demais funcionários do Instituto de Radiologia, pelo empenho em atender às necessidades deste estudo.

Aos pacientes, objetivo final de nossos estudos, que nos ensinam e nos permitem buscar alternativas para minimizar seus sofrimentos.

À Pró-Reitoria de Pós-Graduação da Universidade de São Paulo e à Coordenação de Aperfeiçoamento de Pessoal de Nível Superior (CAPES), pela bolsa do Programa de Demanda Social.

\section{Ao Professor Doutor Sami Arap, Professor Emérito da} Faculdade de Medicina da Universidade de São Paulo, pelos ensinamentos durante minha residência em urologia e por permitir o início desse estudo.

Àqueles injustamente esquecidos e que certamente contribuíram muito para a realização deste trabalho. 


\section{Sumário}

Resumo

Summary

INTRODUÇÃO

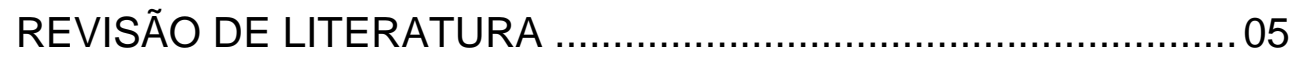

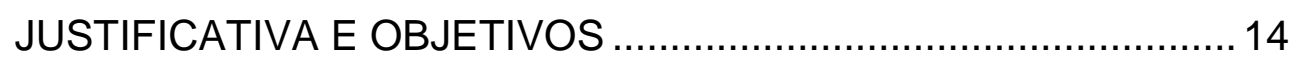

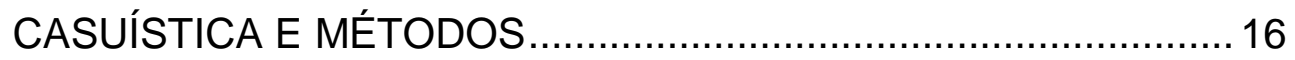

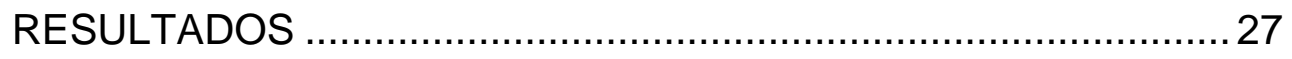

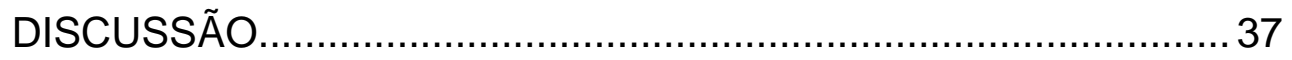

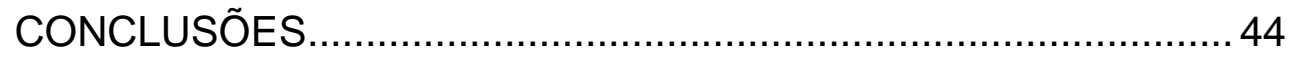

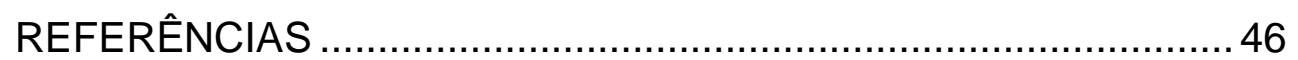




\section{Resumo}

Falci Júnior R. Tratamento do cisto renal simples sintomático por aspiração percutânea e injeção permanente de álcool absoluto em sessão única [tese]. São Paulo. Faculdade de Medicina, Universidade de São Paulo; 2004. 63p.

Introdução: O cisto renal simples é doença benigna, muito prevalente, geralmente assintomática e que raramente requer tratamento. No entanto, na vigência de sintomas, o seu tratamento é acompanhado do desaparecimento dos mesmos. A punção percutânea seguida da esclerose com etanol absoluto (etanol a 99,5\%) é técnica pouco agressiva, que tem como objetivo tratar os cistos renais simples.

Casuística e métodos: No período de julho de 1999 a julho de 2003, foram avaliados prospectivamente 33 pacientes (11 do sexo masculino e 22 do feminino) com idade média de 58,5 \pm 9,7 (34 - 79) anos, portadores de cisto renal simples, diagnosticados pela ultra-sonografia (US), de tamanho variando entre 30 e $1700 \mathrm{ml}$, com dor lombar ipsilateral e sem outra causa de dor. Os pacientes foram submetidos à punção do cisto com agulha 18 gauge, de 20 centímetros, guiada por US em tempo real para assegurar seu esvaziamento completo. Injetou-se etanol absoluto, no volume de um terço do fluido aspirado do cisto, até o máximo de $100 \mathrm{ml}$, pela mesma punção. O seguimento foi realizado através de avaliações clínicas e US consecutivas com intervalos de um, três e seis meses.

Resultados: Dos 33 cistos puncionados, 10 tinham volume aspirado inferior a $100 \mathrm{ml}, 20$ apresentavam entre 100 e $600 \mathrm{ml}$ e 3 eram maiores que $600 \mathrm{ml}$. O volume médio dos cistos foi de 298,2 \pm 346,9 (30 - 
1700) $\mathrm{ml}$, aferido pela US. O volume médio aspirado foi de $290,7 \pm 381,1$ (30-1900) $\mathrm{ml}$ e o volume médio de etanol injetado foi de 58,1 \pm 36,2 (10 100) $\mathrm{ml}$. Os volumes médios observados durante o seguimento foram $47,9 \pm$ $59,4(0-286) \mathrm{ml}$ após um mês, 25,2 \pm 42,8 $(0-208) \mathrm{ml}$ após três meses e $12,7 \pm 30(0-120) \mathrm{ml}$ após seis meses. Houve regressão completa do cisto em 9 dos 10 pacientes com cisto menor que $100 \mathrm{ml}$ e um apresentou volume residual de $6 \mathrm{ml}$. Todos estavam assintomáticos no final do seguimento. Nos 20 pacientes com cisto entre 100 e 600 ml, o cisto desapareceu em 9, enquanto que os demais mantiveram cistos residuais variando de 1,32 a 120 ml. Houve persistência dos sintomas no paciente com cisto residual de 120 $\mathrm{ml}$ e melhora, porém sem desaparecimento dos sintomas em um paciente com cisto residual de $2,5 \mathrm{ml}$. Nos 3 pacientes com cistos maiores que 600 $\mathrm{ml}$, os cistos residuais foram de 51,3, 80 e $100 \mathrm{ml}$. No entanto, os sintomas regrediram nestes pacientes. Um paciente manteve os sintomas apesar do desaparecimento do cisto.

Conclusão: A escleroterapia com etanol em sessão única é um tratamento eficaz para o cisto renal simples sintomático e deve ser oferecida como opção terapêutica.

Descritores: cisto renal, etanol, esclerose. 


\section{Summary}

Falci Júnior R. Treatment of symptomatic simple renal cyst with percutaneous aspiration and single-session permanent $99.5 \%$ ethanol injection [thesis]. São Paulo. "Faculdade de Medicina, Universidade de São Paulo"; 2004. 63p.

Purpose: To evaluate percutaneous single-session sclerotherapy with ethanol without the drainage of the sclerosing agent in patients with symptomatic simple renal cysts that require treatment.

Patients and Methods: A prospective series of 33 (11 male and 22 female) patients between July 1999 and July 2003 with medium age of $58.5 \pm 9.7$ (34-79) years and symptomatic simple renal cysts varying from 30 to $1700 \mathrm{ml}$, diagnosed by ultrasonography (US) were considered eligible for the study. The cysts were punctured under local anesthesia with an 18 gauge, 20 centimeters needle, using US guidance. A volume of ethanol equivalent to one third of the aspirated volume, up to a maximum of 100 milliliters (ml), was injected into the cyst and left there. The patients were reassessed with clinical and US evaluation at one, three and six months.

Results: The medium cyst's volume, measured by the US, was $298.2 \pm 346.9(30-1700) \mathrm{ml}$, being 10 with less than $100 \mathrm{ml}, 20$ between 100 and $600 \mathrm{ml}$ and three larger than $600 \mathrm{ml}$. The procedure was technically feasible in all patients. The aspirated volume was $290.7 \pm 381.1$ (30 - 1900) $\mathrm{ml}$ with the same distribuition. After one, three and six months, the average volume was $47.9 \pm 59.4(0-286) \mathrm{ml}, 25.2 \pm 42.8(0-208) \mathrm{ml}$ and $12.7 \pm 30$ $(0-120) \mathrm{ml}$, respectively. Among the patients with cysts smaller than $100 \mathrm{ml}$, 
in 9 of 10 the cyst disappeared and in one case it ended up the follow-up with a residual cyst of $6 \mathrm{ml}$, estimated by US. All of them were asymptomatic at the end of the follow-up period. In the group of patients with cysts volume varying from 100 to $600 \mathrm{ml}, 9$ of 20 patients had total remission of their cysts while 11 maintained a residual cyst varying from 1.32 to $120 \mathrm{ml}$. In this latter case, with a residual cyst of $120 \mathrm{ml}$, persisting lumbar pain was observed. The three patients who presented with cysts larger than $600 \mathrm{ml}$, a residual cyst of $51.3,80$ and $100 \mathrm{ml}$ was observed. However, total remission of symptoms has been achieved despite residual cyst volume in this group. After this period, 30 patients (91\%) were asymptomatic, showing total remission of the cyst (18 cases) or at least a $90 \%$ decrease in the initial volume (14 cases). One patient (3\%) had a $50 \%$ reduction of the cyst volume and maintenance of the symptoms. One patient (3\%) had substantial improvement of the symptoms, but not disappearance and the remaining patient (3\%) had persisting symptoms despite the total cyst remission.

Conclusion: Single-session percutaneous sclerotherapy with ethanol should be offered as an option for treatment of symptomatic renal cysts since it is highly effective and offers the benefits of a less invasive procedure.

Keywords: renal cyst, ethanol, sclerosis. 
Introdução 


\section{Introdução}

O cisto renal simples é doença benigna que consiste em uma cavidade revestida por epitélio cubóide plano, preenchida por líquido de características semelhantes ao plasma e que não mantém comunicação com o sistema coletor. Acredita-se que seja originado a partir de um néfron ${ }^{1,2}$.

Sua incidência aumenta com a idade. É oito vezes mais freqüente em indivíduos acima dos 80 anos que em indivíduos com menos de 40 . 0 cisto está presente em quase metade das pessoas com mais de 70 anos que se submetem a exame de imagem de rotina ${ }^{2}$ e em $50 \%$ das autópsias em indivíduos com mais de 50 anos ${ }^{3,4}$. Estas evidências e o fato dos cistos aumentarem em número e em tamanho com a idade do paciente ${ }^{2}$ reforçam a idéia de o cisto renal simples ser doença adquirida. Esses cistos representam 80 a $85 \%$ das lesões renais assintomáticas com efeito de massa. E, entre as lesões císticas do rim, $80 \%$ correspondem a cistos classificados como simples ${ }^{5}$.

A maioria dessas lesões é assintomática ${ }^{6,7}$, as quais não requerem tratamento, independentemente do seu tamanho $8,9,10,11,12,13$. No entanto, alguns pacientes têm sintomas decorrentes do cisto renal. O sintoma mais comum é a dor lombar ${ }^{13,14}$. Muito menos freqüentes são os outros sintomas, como hipertensão arterial e policitemia ${ }^{15,16}$; esta, decorrente da produção de eritropoetina ${ }^{17,10}$. Seu tratamento é acompanhado da remissão dos sintomas, na maioria das vezes ${ }^{8,15}$. 
Os tratamentos disponíveis para os cistos renais simples são: exérese ou marsupialização por cirurgia aberta ${ }^{18}$, abordagem e realização do mesmo procedimento por laparoscopia ${ }^{19,20}$ ou por retroperitoneoscopia 21,22,23,24, ressecção percutânea ${ }^{25,26,27}$ e esclerose através de punção ${ }^{28,29,1}$. $\mathrm{Na}$ cirurgia aberta realiza-se a ressecção da parede do cisto estabelecendose comunicação deste com o peritônio ou retroperitônio 5,18,16; na laparoscopia, procedimento semelhante à cirurgia aberta é realizado com a vantagem de evitar a incisão da parede abdominal 19,30,31,32,20,33,34,35,36,37. Na retroperitoneoscopia o acesso ao cisto faz-se através do retroperitônio, por onde se aplicam os mesmos princípios cirúrgicos ${ }^{22}$. A laparoscopia proporcionou avanço notável em relação à cirurgia aberta, porque eliminou as complicações imediatas e tardias das incisões de parede. Concomitantemente desenvolveu-se a ressecção percutânea, técnica através da qual a parede do cisto é retirada através de ressectoscópio com alça e corrente elétrica. Esse procedimento resulta no desaparecimento dos cistos em $50 \%$ dos casos e regressão parcial nos demais, com melhora dos sintomas $^{26}$.

O avanço das técnicas minimamente invasivas e a segurança do diagnóstico e da punção de lesões renais guiadas por ultra-sonografia impulsionaram o desenvolvimento do tratamento dos cistos renais através de punção percutânea, esvaziamento e injeção de um agente esclerosante ${ }^{28}$. Várias substâncias foram empregadas. O etanol, desde sua introdução ${ }^{28}$, tem despertado muito interesse como um destes agentes. 
As diferentes formas de aplicação do etanol e os índices de sucesso variáveis de acordo com a técnica empregada ${ }^{9,13}$ sugerem que o assunto não esteja completamente estudado e que novas formas de aplicação possam melhorar o resultado deste tratamento, que tem a vantagem de ser ambulatorial, feito apenas com anestesia local e de baixo custo. 
Revisão de literatura 


\section{Revisão de literatura}

Até o final dos anos 50 a exploração cirúrgica aberta era o único recurso disponível para o diagnóstico correto das lesões expansivas renais, independentemente do seu aspecto sólido ou cístico, que era desconhecido pelos exames $5,18,38,39,40,41,42,43$. A punção de lesões renais era evitada pela impossibilidade de diferenciação prévia da sua natureza (cística ou sólida) e pelo medo de implante de células neoplásicas no trajeto da agulha no caso de punção inadvertida de neoplasia renal maligna ${ }^{44,45}$.

$\mathrm{O}$ advento da nefrotomografia e da arteriografia renal seletiva deu $\mathrm{O}$ passo inicial na investigação das massas renais, permitindo a diferenciação entre as sólidas e as císticas ${ }^{46}$. Com a possibilidade de caracterização das lesões renais nesses dois grupos, a punção das massas císticas se desenvolveu com objetivo diagnóstico, para complementar os dados obtidos com a arteriografia renal seletiva ${ }^{47,48,49,50}$. Através da punção dos cistos renais pôde-se coletar seu líquido para análise ${ }^{50}$ e injetar contraste iodado, ar ou ambos para estudar sua parede ${ }^{51}$.

Quase uma década mais tarde o aparecimento da ultra-sonografia e da tomografia computadorizada possibilitaram o diagnóstico diferencial das massas renais em císticas e sólidas com muito mais acurácia ${ }^{52}$, resultando em maior segurança na conduta terapêutica de cada grupo ${ }^{53}$. O aprimoramento dessas técnicas e o surgimento da ressonância magnética 
definitivamente permitiram a correta avaliação de $98 \%$ dessas massas $13,54,5,16$

A padronização da técnica de aquisição de imagens por tomografia computadorizada possibilitou a classificação das lesões renais císticas de acordo com sua morfologia, podendo relacioná-la com seu diagnóstico histopatológico.

Essas lesões, avaliadas por tomografia computadorizada, foram classificadas em quatro grupos de acordo com Bosniak ${ }^{55}$, que associa o seu padrão tomográfico à existência de neoplasia renal. O cisto renal simples aparece na tomografia como lesão arredondada, com margens nítidas no parênquima renal adjacente, paredes finas, com conteúdo homogêneo e densidade equivalente à da água ( 0 a 20 unidades de Housfield) e sem realce após a injeção do meio de contraste endovenoso. É uma lesão benigna e classificada como categoria I. A categoria II inclui as lesões que apresentam alguns achados adicionais que não são encontrados nos cistos renais simples, como calcificações, septos finos (menores que um milímetro de espessura) ou conteúdo de alta densidade (superior a 20 unidades de Housfield). Nesta categoria a incidência de neoplasia é de 13\%. A categoria III é composta por lesões císticas mais complexas que na categoria anterior, apresentando septos múltiplos ou espessados, conteúdo heterogêneo ou calcificações no interior. Pode corresponder a cistos infectados, hemorrágicos ou a carcinoma de células renais. Este, em aproximadamente $45 \%$ dessas lesões. A categoria IV apresenta características tomográficas de lesões malignas, com septos grosseiros, captação de contraste, limites 
imprecisos e conteúdo heterogêneo. Até $90 \%$ das lesões classificadas nessa categoria correspondem a carcinoma de células renais. ${ }^{55,56,57}$. A diferenciação entre lesões da categoria II e III requer grande experiência do radiologista e pode ser observador-dependente ${ }^{56}$, mesmo que este seja experiente. Esse fato, associado a impossibilidade de garantir a ausência de malignidade dessas lesões e a probabilidade de seu crescimento ${ }^{58}$, motivam muitos urologistas a propor exploração cirúrgica para todas as lesões císticas renais que não são classificadas como categoria I de Bosniak $31,59,19$

A ultra-sonografia tem sido indicada como exame inicial para avaliação das massas renais, pelo seu baixo custo, simplicidade e acurácia semelhante à tomografia computadorizada, se for utilizado o recurso do Doppler colorido ${ }^{60}$. O diagnóstico seguro de cisto renal simples é obtido quando todos os critérios benignos (conteúdo anecóide, parede extra-renal imperceptível e limite nítido com o parênquima do órgão) são encontrados no exame de ultra-sonografia. Nessa situação, nenhum outro exame precisa ser feito ${ }^{16,55}$. A exploração radiológica adicional é necessária se alguma dessas características for duvidosa, e esta é feita através da tomografia computadorizada ou da ressonância magnética ${ }^{16,61}$.

O tratamento do cisto renal simples desenvolveu-se paralelamente ao aprimoramento dos recursos diagnósticos, visto que foi o avanço nos métodos de imagem e a ausência de neoplasia maligna nesse tipo de lesão que permitiram a realização de técnicas menos agressivas. 
A fluoroscopia foi o primeiro método de imagem que permitiu o acesso por punção às massas renais ${ }^{5,50}$. Por essa técnica tornou-se possível a aspiração, análise citológica e o estudo com duplo contraste dessas massas com melhor acurácia ${ }^{5,62,49,50}$. Mas foram a ultra-sonografia e a tomografia computadorizada que definitivamente possibilitaram o acesso seguro, eficaz e minimamente agressivo a essas lesões ${ }^{63,64}$, motivando o estudo de técnicas para seu tratamento através de punção percutânea.

O primeiro tratamento proposto para os cistos simples renais foi a punção esvaziadora. Logo foi demonstrado que esse método era acompanhado de altos índices de recidiva em curto espaço de tempo 65,9,8,16,29. Para melhorar a eficácia desse tratamento foi proposta a injeção de substâncias no interior da cavidade do cisto após seu esvaziamento. E isso se limitou à injeção do meio de contraste iodado, na época em que não havia segurança para injeção de outras substâncias ${ }^{66,67,68}$. Buscou-se então como alternativa terapêutica a injeção de sangue autólogo, que apresentou $57 \%$ de redução do volume do cisto em 15 meses de seguimento, resultado superior quando comparado com os inexpressivos da aspiração isolada ${ }^{69}$.

A busca por outros agentes esclerosantes foi motivada pela ineficácia da punção esvaziadora isolada ${ }^{65,70}$ e pelo resultado pouco efetivo do sangue autólogo como agente esclerosante ${ }^{69}$. Preconizou-se que o agente esclerosante ideal devesse ser capaz de necrosar o epitélio do cisto e provocar reação inflamatória suficiente para colabar sua cavidade sem agredir os tecidos adjacentes e sem promover efeitos tóxicos sistêmicos, além de ser barato, facilmente disponível e de fácil manipulação ${ }^{29}$. 
A utilização desses agentes cresceu rapidamente na década de 80 , apoiada em métodos de imagem confiáveis. Além da descrição do etanol para 0 tratamento dos cistos renais ${ }^{28}$, diversos outros agentes foram estudados, entre eles iodo-povidona ${ }^{71,8,72}$, betadina ${ }^{73}$, dióxido de carbono ${ }^{74}$, minociclina ${ }^{75}$, tetraciclina ${ }^{29}$, cloreto de sódio hipertônico ${ }^{76}$, cola de fibrina ${ }^{77}$, morruato de sódio ${ }^{78}$, fosfato de bismuto ${ }^{79}$ e etanolamina ${ }^{11}$. Desses, os mais utilizados foram o etanol $29,9,80,81,54,82,10,83,83,75,84,85,86,87,88,1$ e a iodopovidona ${ }^{72,8,71}$ (tabela 1).

Tabela 1: Agentes esclerosantes utilizados no tratamento de cistos renais simples.

AUTOR

Paananen e cols., $2001^{1}$

De Dominics e cols., $2001^{87}$

Liatsikos e cols., $2000^{29}$

Chung e cols., $2000^{9}$

Fontana e cols., $1999^{13}$

Phelan e cols., $1999^{8}$

Sanz Chinesta e cols., $1997^{71}$

Porpiglia e cols., $1996^{80}$

Pfister e cols., $1996^{54}$

Saracino e cols., $19966^{89}$

Kabaalioglu e cols., $1996^{76}$

El-Diasty e cols., $1995^{82}$

Aboutaieb e cols., $1995^{10}$

Ibnatya e cols., 1995

Santoriello e cols., $1994^{77}$

Tabata e cols., $1994^{74}$

Zama, $1994^{8}$

Veltri e cols., $1993^{90}$

Nishimura e cols., $1993^{75}$

Ohkawa e cols., $1993^{91}$

Nishikawa e cols., $1992^{92}$

Garcia Novio e cols., $1990{ }^{86}$

Bianchi e cols., $1990^{84}$

Holmberg e Hietala., $1989^{79}$

Shinoda e cols., $1988^{72}$

Ozgur e cols., 1988

Wernecke e cols., $1985^{69}$

Bean, $1981^{28}$

Lindemann e cols., $1979^{93}$

Raskin e cols., $1975^{66}$
PACIENTES

SUBSTÂNCIA

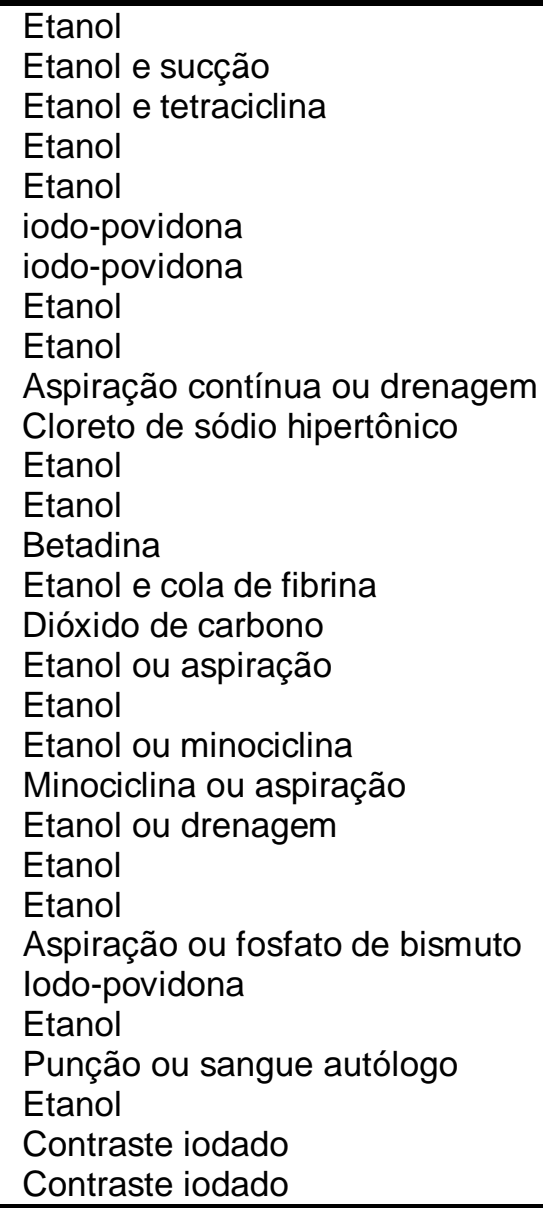


O etanol age nas células do epitélio que reveste o cisto. Através da difusão pela membrana celular ele produz desidratação, lise da membrana e desnaturação protéica. Esse fenômeno é seguido de reação inflamatória com trombose e oclusão de pequenos vasos, gerando a necrose de coagulação ${ }^{94}$. A necrose do epitélio que reveste o cisto renal simples ocorre após um a quatro minutos de contato com o etanol e a penetração da sua cápsula após quatro a 12 horas ${ }^{28}$.

O etanol é considerado o agente mais seguro, pelo fato de seu metabolismo ${ }^{95}$ e mecanismo de ação ${ }^{94}$ serem conhecidos. O nível sérico atingido após a injeção no interior do cisto é seguro e inferior ao nível tóxico 1,96,95; por isso tem merecido a preferência da maioria dos autores (figura 1).

Figura 1: Agentes esclerosantes mais utilizados para tratamento do cisto renal simples por 34 autores.

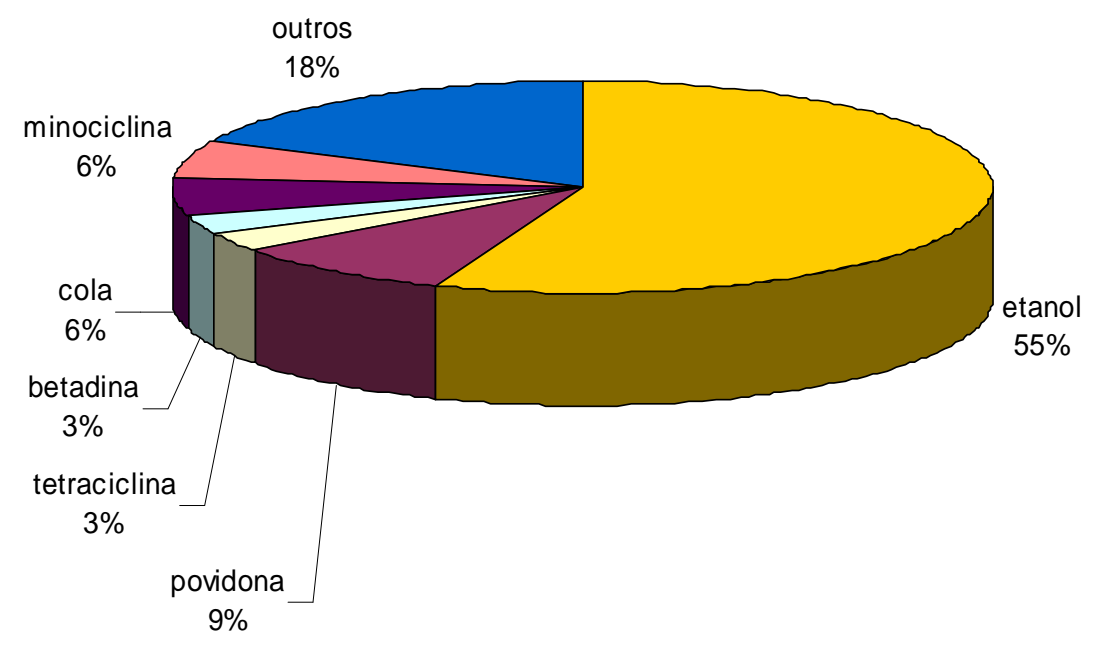


Por esse motivo o etanol também foi utilizado em outros tecidos com o objetivo de provocar necrose. Seu uso é bem estudado para o tratamento do carcinoma hepatocelular ${ }^{97}$, da hiperplasia prostática benigna ${ }^{98,99}$, das doenças da adrenal ${ }^{100}$, das doenças da tireóide ${ }^{101}$, das doenças da paratireóide ${ }^{102}$ e em casos isolados de tumor de bexiga ${ }^{103}$, de pâncreas ${ }^{104}$ e de pulmão ${ }^{105}$.

Embora seja considerado um agente seguro, as técnicas descritas até o presente para a utilização do etanol no tratamento dos cistos renais simples preconizam sua drenagem após vinte minutos de permanência no interior da lesão. E, para que isso seja realizado, é necessário o posicionamento de um cateter no interior do cisto, que é usado para seu esvaziamento, introdução do agente esclerosante e sua drenagem após 20 minutos ${ }^{9,54,13}$. Por essa técnica, obtém-se até $96 \%$ de remissão dos cistos, quando realizada três sessões consecutivas e com intervalo de 12 horas ${ }^{80,81}$. Os resultados são piores se realizada apenas uma sessão, atingido apenas $57 \%$ de sucesso ${ }^{9}$. Por isso, tem-se preconizado a repetição com intervalos curtos, de 24 a 48 horas através do cateter que pode ser deixado no interior do cisto nesse período ${ }^{13,29,80}$.

O sucesso da escleroterapia é dependente de vários fatores, entre eles do tamanho do cisto ${ }^{28}$, do agente esclerosante ${ }^{72,8,1}$ e o número de sessões realizadas ${ }^{9}$.

O melhor resultado observado com múltiplas sessões comparado à sessão única ${ }^{9}$ e o mecanismo de ação postulado para a destruição do cisto ${ }^{28}$ sugerem que o contato do etanol com a parede do cisto deva ser maior 
que os 20 minutos descritos até o presente, o que motiva o aperfeiçoamento desse método que tem as vantagens de ser eficaz, minimamente invasivo e de baixo custo. 
Justificativa e Objetivos 


\section{Justificativa e Objetivos}

Apesar da pequena porcentagem de pacientes portadores de cisto renal simples necessitarem de tratamento, dada a alta prevalência da doença, esta quantidade é significativa. Várias são as técnicas disponíveis e a natureza benigna da lesão justifica a busca por procedimentos minimamente agressivos que resultem em menor morbidade, menor tempo de internação hospitalar e, portanto, menor custo. Entre os fatores determinantes do sucesso do tratamento dos cistos renais simples por esclerose com etanol, um dos mais importantes é o tempo de contato dessa substância com a parede do cisto. É provável que o contato contínuo do etanol com a parede do cisto possa atingir resultado equivalente às múltiplas sessões de esclerose com drenagem do agente. Este fato, associado à busca pelo aperfeiçoamento do procedimento motivam o presente projeto.

O objetivo deste estudo é avaliar a eficácia do tratamento do cisto renal simples por aspiração percutânea e esclerose com etanol absoluto em uma única sessão, sem drenagem do agente esclerosante.

Este projeto de pesquisa foi aprovado pela Comissão de Ética para Análise de Projetos de Pesquisa (CAPPesq) do Hospital das Clínicas da Faculdade de Medicina da Universidade de São Paulo. 
Casuística e Métodos 


\section{Casuística e Métodos}

Foram estudados prospectivamente 33 pacientes ( 11 homens e 22 mulheres) no período de julho de 1999 a julho de 2003 com cistos renais simples diagnosticados por ultra-sonografia e dor lombar, sendo 18 indivíduos brancos, 7 negros e 8 pardos, com idade média de 58,5 \pm 9,7 (34 - 79) anos (figura 2). A dor lombar era ipsilateral ao cisto, em peso, nãocólica, de caráter insidioso, sem relação com a posição e de intensidade geralmente moderada. O volume médio do cisto foi de $298,2 \pm 346,9 \mathrm{ml}$, variando de 30 a $1700 \mathrm{ml}$ (tabela 2).

Figura 2: Distribuição etária dos pacientes submetidos à esclerose do cisto renal simples.

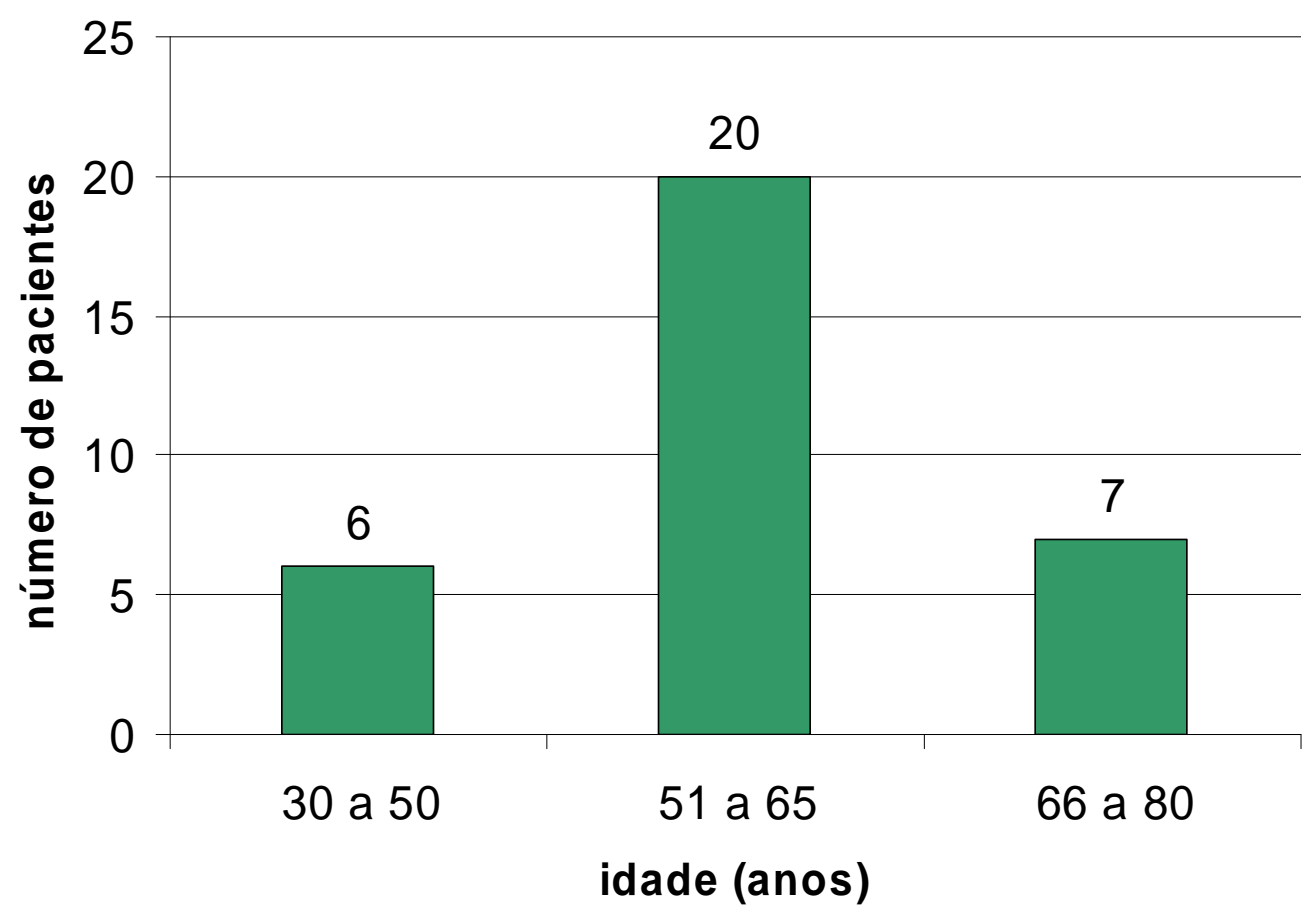


Tabela 2: Identificação e características dos pacientes incluídos no estudo.

\begin{tabular}{|c|c|c|c|c|c|c|c|}
\hline Caso & Registro & $\begin{array}{l}\text { Idade } \\
\text { (anos) }\end{array}$ & Sexo & Cor & $\begin{array}{c}\text { Volume } \\
\text { do cisto } \\
\text { (ml) }\end{array}$ & $\begin{array}{l}\text { Intensidade } \\
\text { da dor }\end{array}$ & $\begin{array}{l}\text { Tipo da } \\
\text { dor }\end{array}$ \\
\hline 1 & $\mathrm{HAOC03/7621}$ & 68 & $\mathrm{~m}$ & branca & 1063 & fraca & Peso \\
\hline 2 & $13498842 f$ & 69 & $\mathrm{~m}$ & branca & 807 & moderada & peso \\
\hline 3 & $3360221 \mathrm{c}$ & 63 & $f$ & parda & 54 & moderada & peso \\
\hline 4 & $3386222 d$ & 49 & $f$ & negra & 160 & moderada & peso \\
\hline 5 & $13498488 d$ & 60 & $\mathrm{~m}$ & parda & 1700 & moderada & peso \\
\hline 6 & $2377550 e$ & 62 & $f$ & branca & 215 & moderada & peso \\
\hline 7 & $3111582 k$ & 53 & $f$ & parda & 540 & moderada & peso \\
\hline 8 & $5062623 b$ & 72 & $f$ & branca & 36 & moderada & peso \\
\hline 9 & $13475485 a$ & 34 & $f$ & parda & 296 & forte & peso \\
\hline 10 & $2030263 c$ & 64 & $f$ & branca & 150 & moderada & peso \\
\hline 11 & $13516751 d$ & 57 & $\mathrm{~m}$ & parda & 178 & moderada & peso \\
\hline 12 & 13439270j & 51 & $f$ & branca & 140 & moderada & peso \\
\hline 13 & $13436177 \mathrm{k}$ & 65 & $f$ & parda & 175 & moderada & peso \\
\hline 14 & $13532772 e$ & 69 & $f$ & branca & 330 & forte & peso \\
\hline 15 & 13445446h & 55 & $\mathrm{~m}$ & branca & 49 & moderada & peso \\
\hline 16 & $3118403 c$ & 65 & $f$ & parda & 368 & moderada & peso \\
\hline 17 & $13534670 a$ & 44 & $\mathrm{~m}$ & branca & 80 & forte & queimação \\
\hline 18 & 2854967d & 51 & $f$ & branca & 280 & moderada & peso \\
\hline 19 & $2092859 \mathrm{~g}$ & 55 & $f$ & branca & 86 & moderada & peso \\
\hline 20 & $13581731 d$ & 66 & $\mathrm{~m}$ & branca & 150 & moderada & peso \\
\hline 21 & $3224437 \mathrm{~h}$ & 59 & $f$ & branca & 115 & moderada & peso \\
\hline 22 & HAOC91/3619 & 79 & $\mathrm{~m}$ & branca & 63 & fraca & peso \\
\hline 23 & 2063230d & 51 & $f$ & negra & 30 & moderada & peso \\
\hline 24 & 3241600h & 49 & $f$ & negra & 120 & forte & peso \\
\hline 25 & $2234173 c$ & 58 & $f$ & negra & 580 & moderada & peso \\
\hline 26 & $13497987 a$ & 44 & $f$ & branca & 240 & forte & peso \\
\hline 28 & $2094246 e$ & 50 & $f$ & negra & 45 & moderada & peso \\
\hline 29 & $13463158 b$ & 60 & $f$ & branca & 42 & moderada & peso \\
\hline 30 & $13600161 \mathrm{j}$ & 63 & $\mathrm{~m}$ & branca & 320 & moderada & peso \\
\hline 30 & $13586528 e$ & 51 & $\mathrm{~m}$ & parda & 400 & moderada & peso \\
\hline 31 & $2182465 a$ & 58 & $f$ & negra & 480 & moderada & peso \\
\hline 32 & $3121751 \mathrm{~g}$ & 77 & $f$ & branca & 30 & moderada & peso \\
\hline 33 & $3105869 f$ & 59 & $\mathrm{~m}$ & negra & 520 & moderada & peso \\
\hline
\end{tabular}

m: masculino; f: feminino

A dor foi classificada quanto sua localização, característica, tempo de evolução e intensidade, que foi quantificada através de escala visual numérica ${ }^{106,107}$. Por este método, cada paciente foi instruído a se posicionar em uma escala variando de zero a dez, representando o zero a ausência de dor e o dez a maior dor conhecida pelo paciente ${ }^{108}$. Com isso, a dor ou 
desconforto vivenciado pelo paciente foi traduzido por um número entre zero e 10. A pontuação média dos pacientes previamente ao tratamento do cisto foi de $5.2 \pm 1$, variando de 3 a 8 pontos. A maioria dos pacientes (66\%) atribuiu-se nota 5 e 6 em escala visual numérica de 0 a 10. A dor foi classificada como em peso por 32 pacientes e em queimação por um. Vinte e seis indivíduos julgaram a dor de intensidade moderada, dois de intensidade fraca e cinco, forte. Esses pacientes, que apresentavam cisto simples, dor ipsilateral ao cisto com as características descritas acima, ausência e de outros diagnósticos que pudessem explicar a dor e desejo de tratar, foram considerados elegíveis para o estudo. Os portadores de rim único ou mal-formações do trato urinário foram excluídos.

O diagnóstico de cisto renal simples foi obtido através de ultrasonografia contendo as seguintes características: lesão arrendondada, com conteúdo anecóide, circunscrita por paredes finas, com limite nítido com o parênquima renal adjacente e sem septos no seu interior ${ }^{55}$ (figura 3). 
Figura 3: Cisto renal simples visto através de ultra-sonografia.

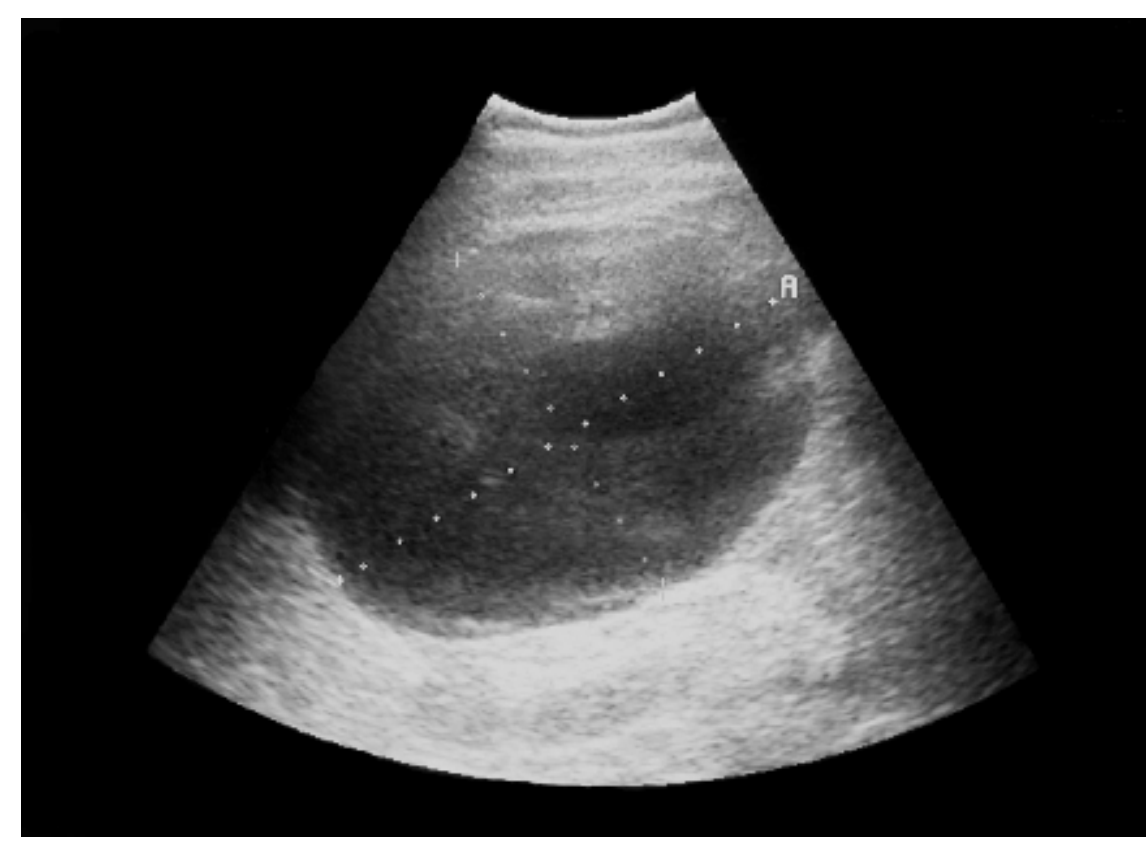

O cisto foi classificado como exofítico quando se projetava externamente ao rim ou intra-renal quando seu maior diâmetro encontravase no interior do parênquima renal. $O$ volume do cisto foi estimado pela obtenção dos três maiores diâmetros multiplicados pela constante 0,5236 , que corresponde à adaptação da fórmula utilizada para o cálculo do volume de uma esfera: 
Volume da esfera $=4 / 3 q^{*} r^{3}$

Como diâmetro $=2 \times$ raio $(d=2 r)$, temos:

Volume da esfera $=4 / 3 \pi(d / 2)^{3}$

Volume da esfera $=\frac{\mathbb{I d}{ }^{3}}{6}$

Como $9=3,1416$ :

Volume da esfera $=0,5236 \mathrm{~d}^{3}$

Como o cisto renal não é uma esfera perfeita, utilizam-se três diâmetros diferentes para minimizar o erro. Portanto:

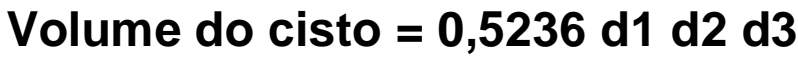

O procedimento foi realizado em caráter ambulatorial. Foi promovida analgesia sistêmica com 1 miligrama $(\mathrm{mg})$ de meperidina por quilo de peso por via intramuscular 30 minutos antes.

Iniciou-se pela realização de ultra-sonografia com o objetivo de confirmar o diagnóstico, estimar o volume do cisto (figura 4) e localizar o melhor local de punção. 
Figura 4: Aferição do volume do cisto por ultra-sonografia previamente à punção esvaziadora.

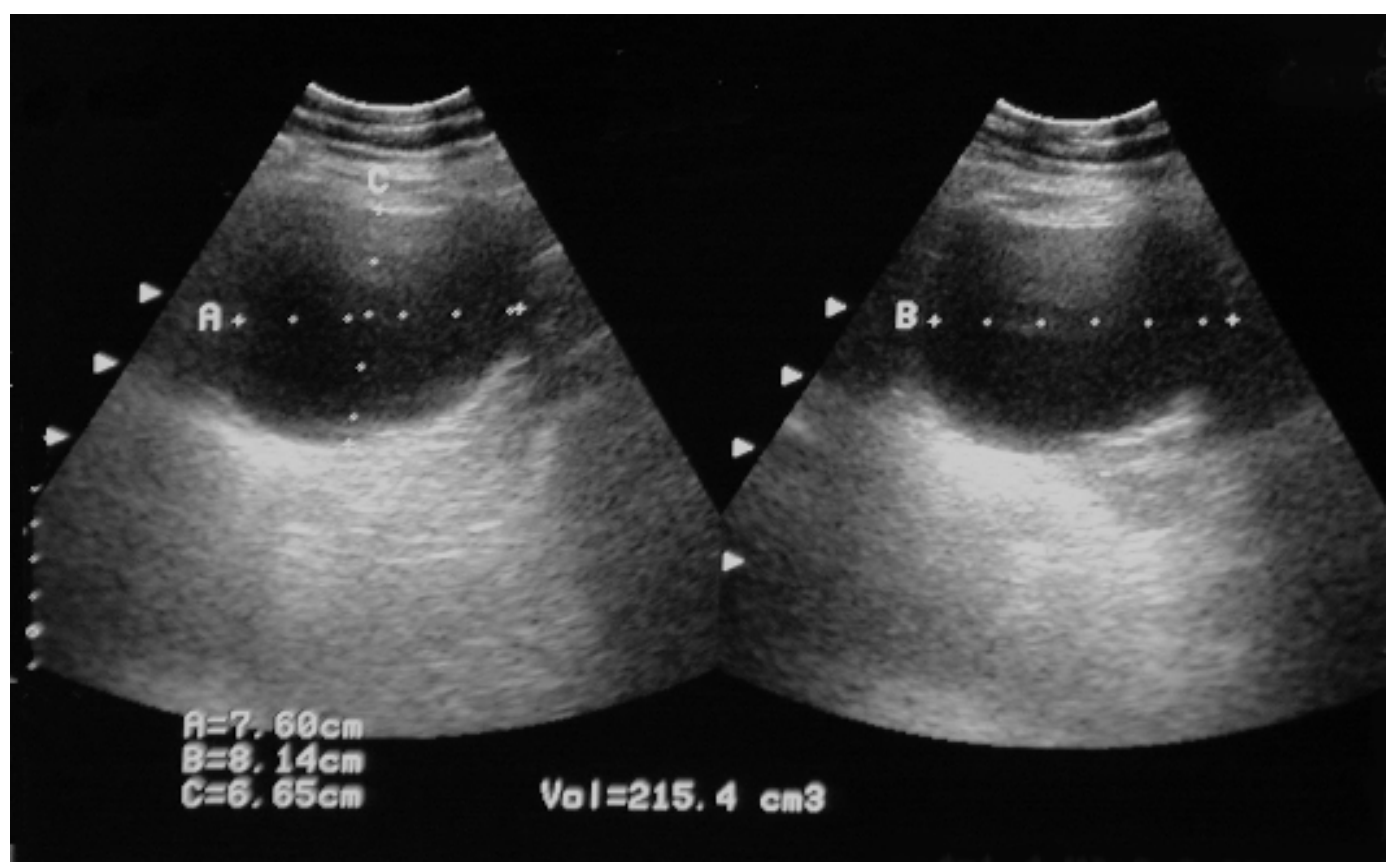

Realizou-se anti-sepsia com iodo povidona em solução alcoólica e colocação de campos estéreis. Seguiu-se anestesia local com lidocaína em concentração de $2 \%$ sem vasoconstritor e punção com agulha 18 gauge* $^{\star}$ de diâmetro e com 20 cm de comprimento (figura 5).

Figura 5: Agulha 18 gauge de 20 centímetros utilizada para punção, esvaziamento do cisto e injeção do etanol no seu interior. 
O posicionamento da agulha no interior do cisto foi orientado por ultra-sonografia em tempo real (figura 6).

Figura 6: Posição da ponta da agulha no interior do cisto.

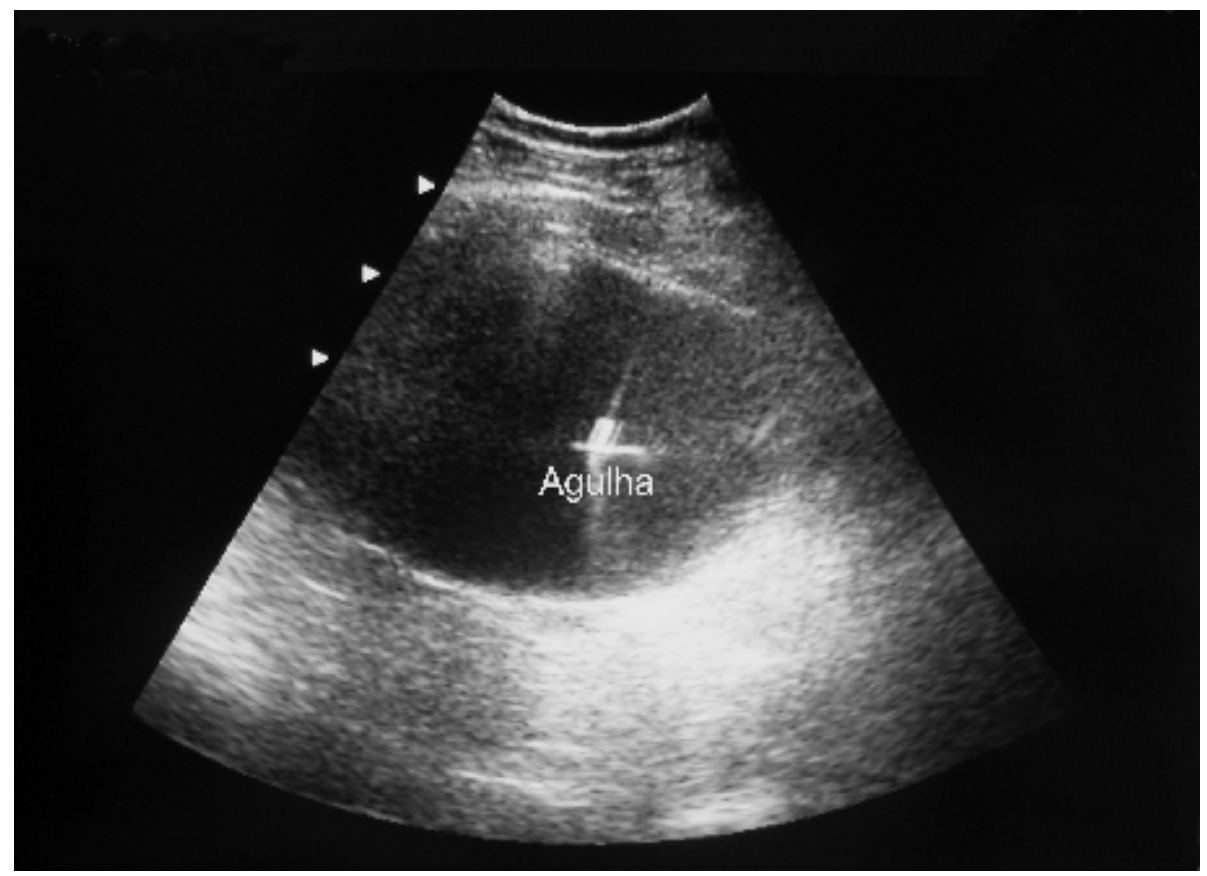

Uma vez certificado o posicionamento da agulha, colheu-se uma amostra do fluido para análise bioquímica e citológica. Procedeu-se o esvaziamento total do cisto, controlado por ultra-sonografia em tempo real com o objetivo de checar a posição da agulha e garantir seu completo esvaziamento (figura 7). 
Figura 7: Imagem obtida por ultra-sonografia após o esvaziamento completo do cisto renal.

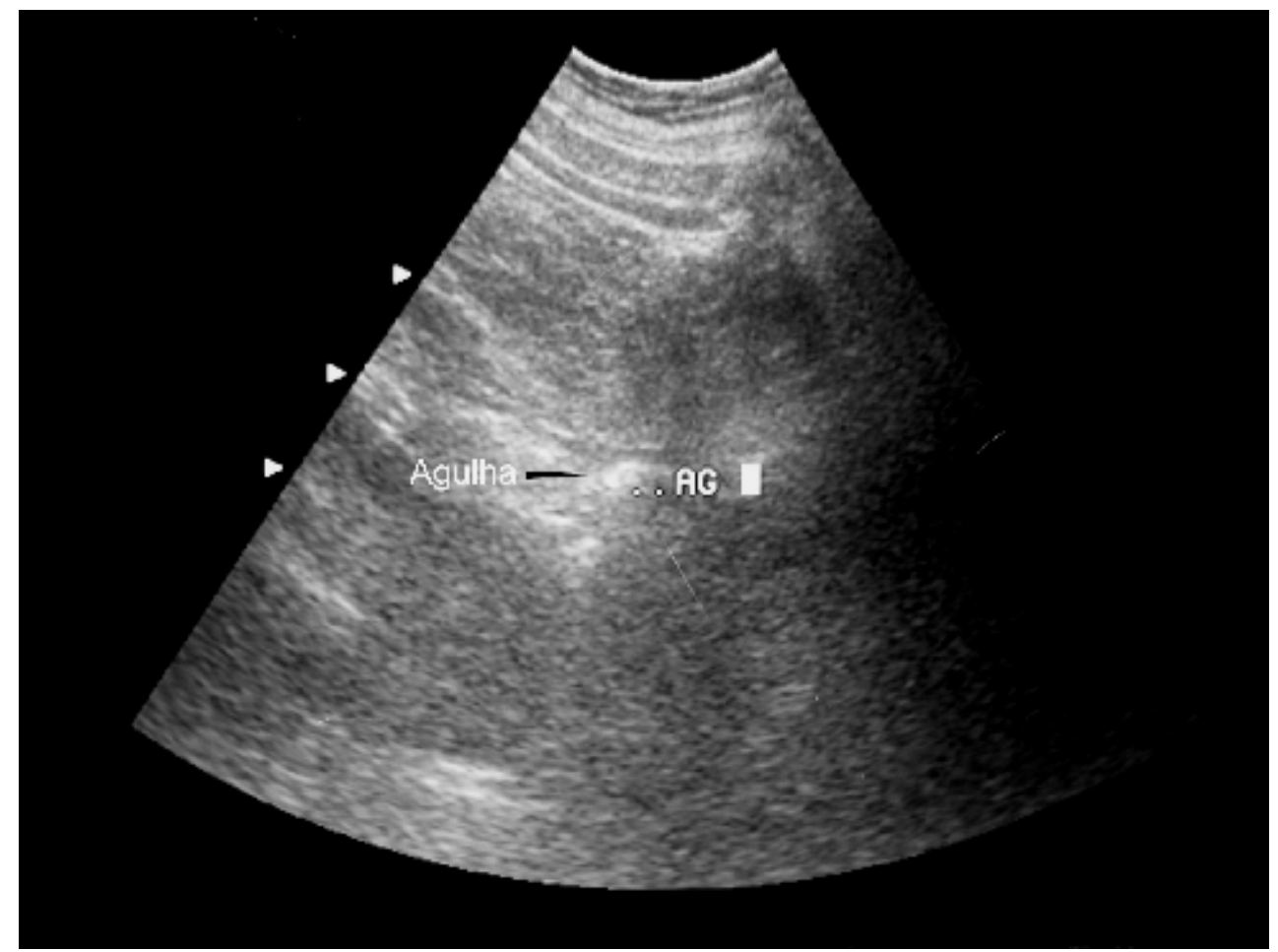

Seguiu-se a injeção de etanol absoluto (etanol a 99,5\%) no volume de um terço do volume do fluido aspirado, até o máximo de $100 \mathrm{ml}$. A injeção do etanol foi monitorizada por Doppler colorido a fim de verificar a ausência de extravasamento do agente (figura 8). A agulha foi retirada, o etanol deixado no interior do cisto e o pacientes encaminhado para observação. 
Figura 8: Ultra-sonografia com Doppler utilizada durante a injeção do etanol no interior do cisto.

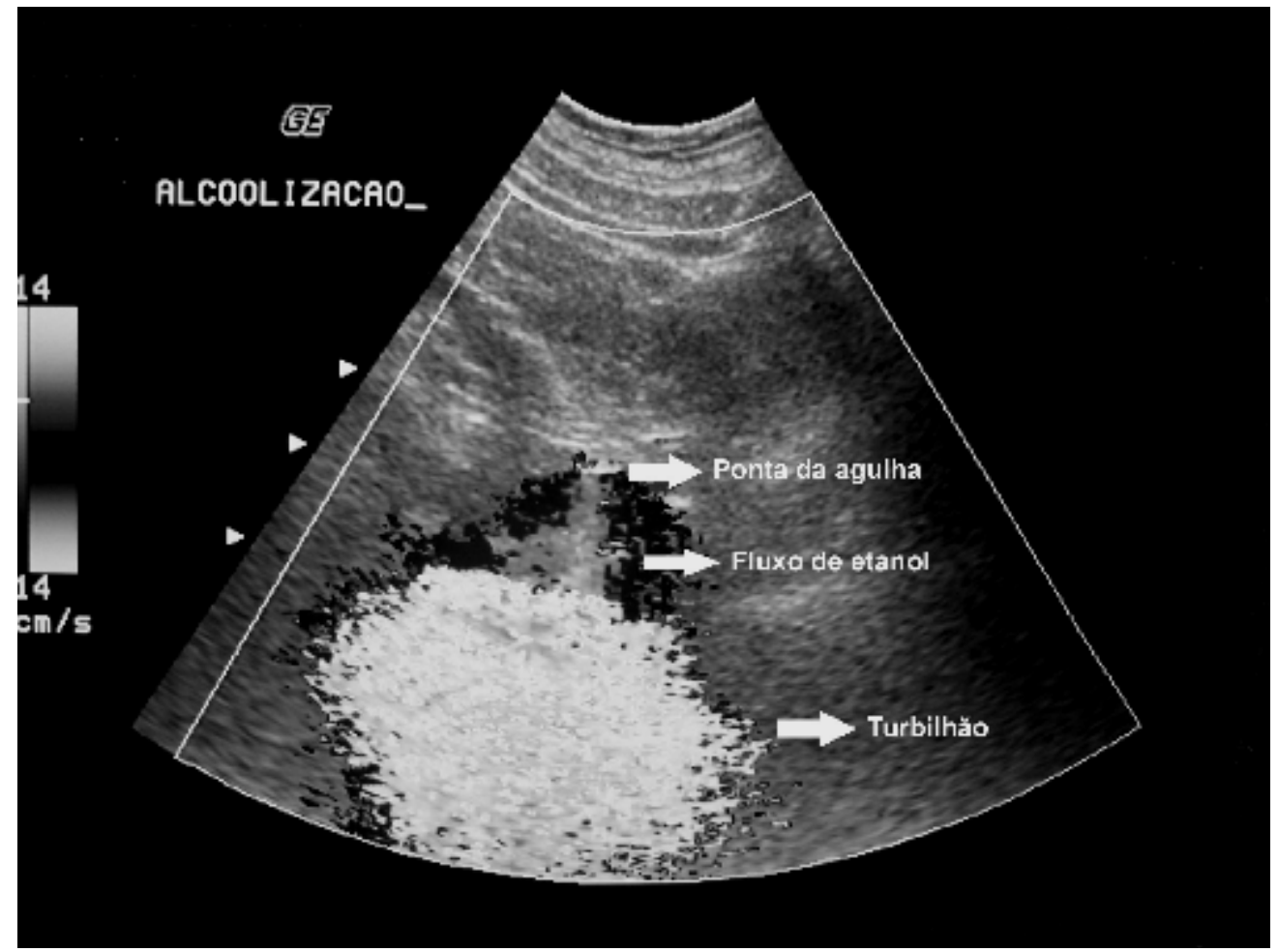

Os analgésicos utilizados após o procedimento foram $10 \mathrm{mg}$ de butilescopolamina com $250 \mathrm{mg}$ de dipirona sódica por via oral, $100 \mathrm{mg}$ de cetoprofeno por via intramuscular e $1 \mathrm{mg}$ de meperidina por quilo de peso corpóreo por via intramuscular, em ordem progressiva, conforme solicitação do paciente.

O resultado do procedimento foi avaliado após seis meses. O seguimento foi realizado através de consulta médica onde foi avaliada a melhora dos sintomas através de escala visual numérica, mesmo método 
usado na avaliação antes do procedimento e ultra-sonografia com intervalo de um, três e seis meses após o procedimento. O mesmo radiologista que participou da punção para tratamento do cisto realizou o exame de controle com atenção para o segmento renal onde o cisto havia sido esclerosado, para a pesquisa de cisto residual e aferição do seu volume quando presente. O restante da via urinária também foi analisado para a pesquisa de acometimento secundário.

As variáveis contínuas foram avaliadas através da média, desviopadrão e valores máximo e mínimo. As categóricas foram estudadas através das freqüências absoluta e relativa. As medidas foram comparadas pelo teste $\mathrm{t}$ de Student. Utilizou-se o qui-quadrado de Pearson e o teste de Wilcoxon não paramétrico para comparação de variáveis categóricas. A relação entre o volume inicial do cisto e o volume residual foi avaliada pela correlação linear de Pearson. Para o processamento dos dados foi utilizado o programa STATA, versão 8.0 Intercooled, Stata Coorporation, Texas, Estados Unidos, com direitos autorais estabelecidos de 1984 a 2003. 
Resultados 


\section{Resultados}

O volume médio dos cistos aferido por ultra-sonografia foi $298,2 \pm$ $346,9 \mathrm{ml}$, variando de 30 a $1700 \mathrm{ml}$. Dez pacientes apresentavam cistos com volume inferior a $100 \mathrm{ml}, 20$ variando de 100 a $600 \mathrm{ml}$ e três com volume superior a $600 \mathrm{ml}$ (figura 9). O cisto foi classificado como exofítico em 23 casos e intra-renal nos 10 restantes.

Figura 9: Distribuição do volume dos cistos nos pacientes com cistos renais sintomáticos.

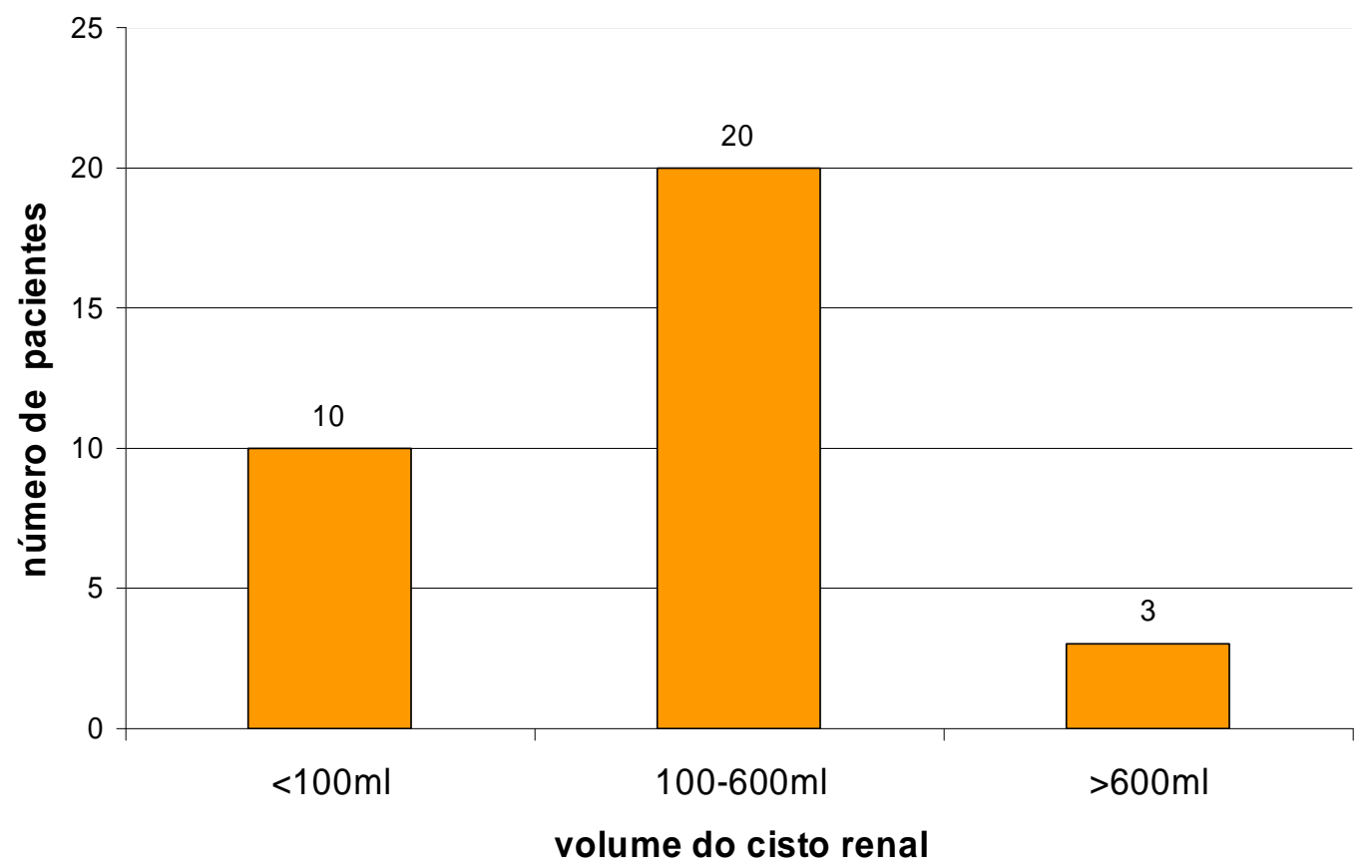


O volume médio aspirado foi de 290,7 $\pm 381,1 \mathrm{ml}(30-1900 \mathrm{ml}) \mathrm{de}$ fluido do cisto e foram injetados $58,1 \pm 36,2 \mathrm{ml}(10-100 \mathrm{ml})$ de etanol. Não houve diferença estatística significativa entre o volume aferido pela ultrasonografia e o volume aspirado do cisto $(p=0,25)$.

Os cistos classificados como intra-renais eram significativamente menores que os exofíticos, com $p=0,001$ (tabela 3).

Tabela 3: Distribuição do volume do cisto de acordo com sua localização.

\begin{tabular}{cccc}
\hline $\begin{array}{c}\text { Tamanho inicial } \\
\text { do cisto }\end{array}$ & Exofítico & Intra-renal & Total \\
\hline menor que $100 \mathrm{ml}$ & 2 & 8 & 10 \\
100 a $600 \mathrm{ml}$ & 17 & 3 & 20 \\
maior que $600 \mathrm{ml}$ & 3 & 0 & 3 \\
\hline Total & 22 & $\mathrm{p}=0,001$ & 33 \\
\hline
\end{tabular}

A citologia foi negativa em todos os casos e a análise bioquímica do fluido aspirado revelou sódio, potássio, uréia e creatinina em concentrações semelhantes às do plasma.

O tempo de internação variou de 6 a 24 horas. Dez pacientes (30\%) não necessitaram de qualquer analgésico após o procedimento, 15 (45\%) receberam apenas butil-escopolamina e dipirona por via oral, 4 (12\%) 
receberam butil-escopolamina, dipirona e cetoprofeno e 4 pacientes (12\%) necessitaram de meperidina além das demais drogas como analgésicos (tabela 4).

Tabela 4: Quantidade de analgésicos ministrados aos pacientes durante a internação, após o procedimento.

\begin{tabular}{ccccc}
\hline Caso & $\begin{array}{c}\text { Escopolamina } \\
\text { (VO em mg) }\end{array}$ & $\begin{array}{c}\text { Dipirona } \\
\text { (VO em mg) }\end{array}$ & $\begin{array}{c}\text { Cetoprofeno } \\
\text { (IM em mg) }\end{array}$ & $\begin{array}{c}\text { Meperidina } \\
\text { (IM em mg } / \mathrm{kg})\end{array}$ \\
\hline 1 & 40 & 1000 & 0 & 0 \\
2 & 0 & 0 & 0 & 0 \\
3 & 20 & 500 & 0 & 0 \\
4 & 10 & 250 & 0 & 0 \\
5 & 0 & 0 & 0 & 0 \\
6 & 10 & 250 & 0 & 0 \\
7 & 40 & 1000 & 0 & 1 \\
8 & 40 & 1000 & 100 & 1 \\
9 & 40 & 1000 & 200 & 0 \\
10 & 0 & 0 & 0 & 0 \\
11 & 20 & 500 & 0 & 0 \\
12 & 20 & 500 & 0 & 0 \\
13 & 0 & 0 & 0 & 0 \\
14 & 30 & 750 & 0 & 0 \\
15 & 0 & 0 & 0 & 1 \\
16 & 40 & 1000 & 100 & 0 \\
17 & 40 & 1000 & 200 & 0 \\
18 & 30 & 750 & 0 & 0 \\
19 & 10 & 250 & 0 & 0 \\
20 & 0 & 0 & 0 & 0 \\
21 & 10 & 250 & 0 & 0 \\
22 & 0 & 0 & 0 & 1 \\
23 & 10 & 250 & 100 & 0 \\
24 & 40 & 1000 & 200 & 0 \\
25 & 30 & 750 & 0 & 0 \\
26 & 20 & 500 & 100 & 0 \\
27 & 0 & 0 & 0 & 0 \\
28 & 20 & 500 & 100 & 0 \\
29 & 10 & 250 & 0 & 0 \\
30 & 20 & 500 & 0 & 0 \\
31 & 0 & 0 & 0 & 0 \\
32 & 0 & 250 & 0 & 0 \\
33 & 10 & & 0 & 0 \\
\hline $0: v 1 a$ & 0 & 0 & 0 & 0 \\
\hline
\end{tabular}

VO: via oral; IM: intramuscular 
O seguimento clínico variou de 6 a 48 meses. A média do volume um mês após a esclerose foi de 47,9 $\pm 59,4 \mathrm{ml}$, variando de 0 a $286 \mathrm{ml}$; após três meses foi de $25,2 \pm 42,8 \mathrm{ml}$, variando de 0 a $208 \mathrm{ml}$, e após seis meses foi de $12,7 \pm 30 \mathrm{ml}$, variando de 0 a $120 \mathrm{ml}$. Após seis meses de seguimento foi observada regressão completa do cisto em 9 dos 10 pacientes com cistos iniciais inferiores a $100 \mathrm{ml}$, em 9 dos 20 pacientes com cistos iniciais entre 100 e $600 \mathrm{ml}$ e em nenhum dos pacientes cujos cistos tinham volume inicial superior a $600 \mathrm{ml}$. Regressão parcial ocorreu nos demais: um único caso no grupo dos cistos inferiores a $100 \mathrm{ml}$ permaneceu com cisto residual de $6 \mathrm{ml}$ (caso 19); onze no grupo de 100 a $600 \mathrm{ml}$ tiveram cistos residuais que variaram entre 1,32 a $120 \mathrm{ml}(\operatorname{casos} 4,7,10,11,13,18,25,29,30,31$ e 33) e três no grupo dos cistos maiores de $600 \mathrm{ml}$ que variaram de 51,3 a $100 \mathrm{ml}$ (casos 1, 2 e 5) (tabela 5). No total, 18 pacientes apresentaram desaparecimento do cisto (figura 10) e 15 regressão parcial (figura 11) significativa em relação ao volume inicial $(p=0,0000)$.

Tabela 5: Resultado quanto à regressão do tamanho do cisto.

\begin{tabular}{cccc}
\hline Tamanho inicial & Regressão total & Regressão parcial & Total \\
\hline menor que $100 \mathrm{ml}$ & 9 & 1 & 10 \\
100 a $600 \mathrm{ml}$ & 9 & 11 & 20 \\
maior que $600 \mathrm{ml}$ & 0 & 3 & 3 \\
\hline Total & 18 & 15 & 33 \\
\hline
\end{tabular}


Figura 10: Imagem obtida por ultra-sonografia demonstrando cicatriz renal no local onde o cisto foi tratado, ilustrando sua regressão completa.

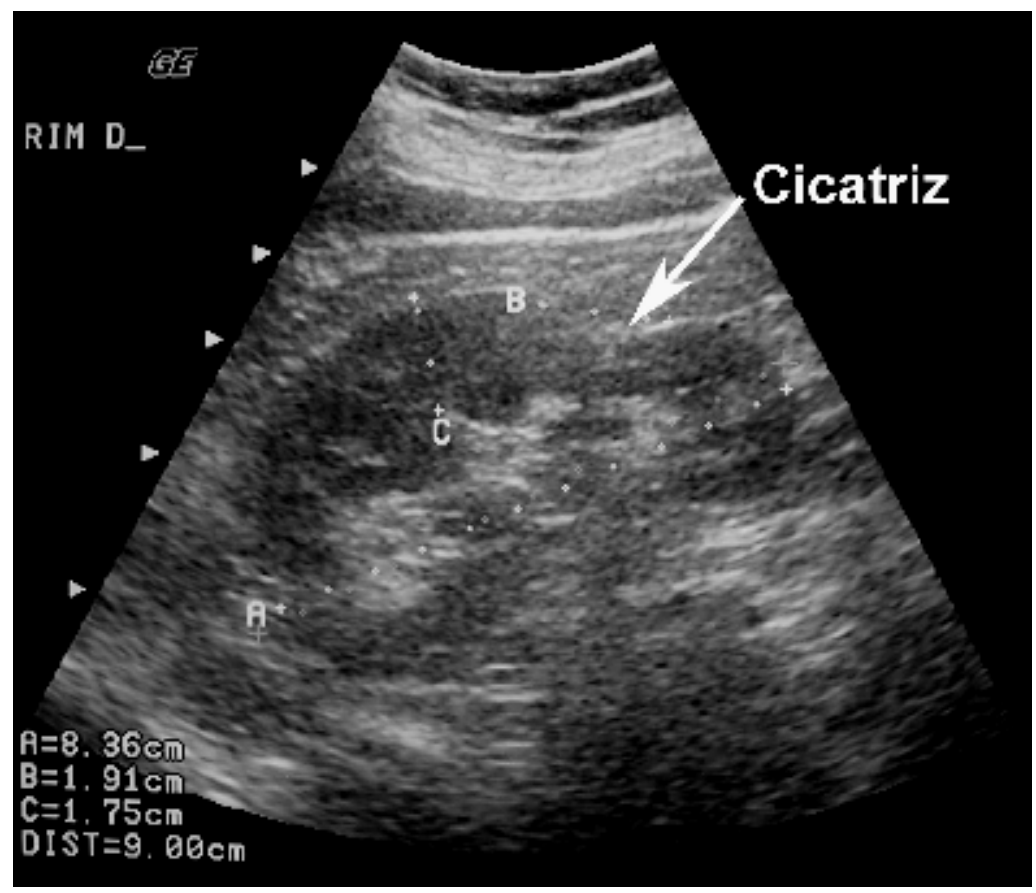

Figura 11: Imagem obtida por ultra-sonografia de cisto residual após seis meses de esclerose com etanol.

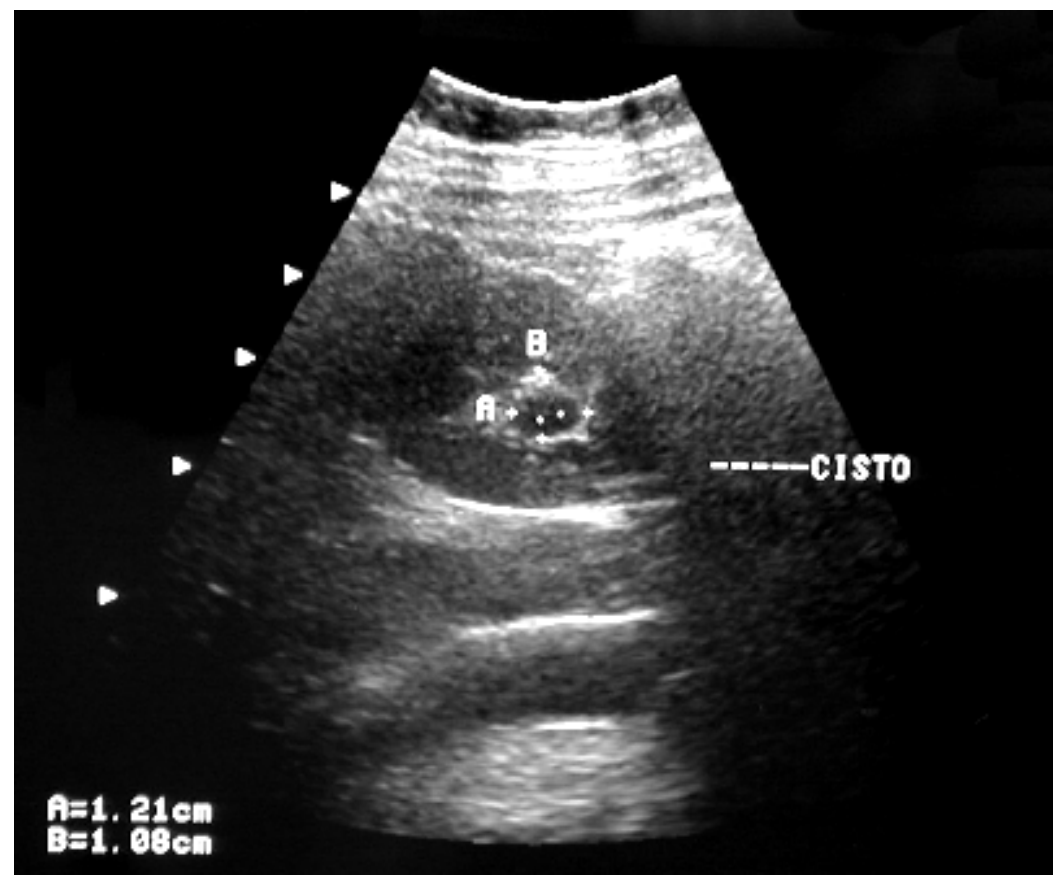


A diminuição do volume do cisto foi gradual, progressiva e mais intensa no primeiro mês, porém significativa a cada período do seguimento (tabela 6).

Tabela 6: Comparação do volume inicial do cisto e após sua esclerose, com um, três e seis meses, aferidos por ultra-sonografia.

\begin{tabular}{|c|c|c|c|c|}
\hline Caso & Volume inicial (ml) & 1 mês (ml) & 3 meses $(\mathrm{ml})$ & 6 meses $(\mathrm{ml})$ \\
\hline$\overline{1}$ & 1063 & 115 & 108 & 80 \\
\hline 2 & 807 & 78,7 & 70,8 & 51,3 \\
\hline 3 & 54 & 34 & 5 & 0 \\
\hline 4 & 160 & 40 & 23 & 10 \\
\hline 5 & 1700 & 100,7 & 102,6 & 100 \\
\hline 6 & 215 & 58 & 23 & 0 \\
\hline 7 & 540 & 286 & 208 & 120 \\
\hline 8 & 36 & 12 & 0 & 0 \\
\hline 9 & 296 & 14 & 6,8 & 0 \\
\hline 10 & 150 & 37 & 10 & 2,6 \\
\hline 11 & 178 & 61,5 & 53 & 2,5 \\
\hline 12 & 140 & 17,3 & 0 & 0 \\
\hline 13 & 175 & 25 & 5 & 1,32 \\
\hline 14 & 330 & 90,7 & 30 & 0 \\
\hline 15 & 49 & 4,7 & 3 & 0 \\
\hline 16 & 368 & 70 & 3,6 & 0 \\
\hline 17 & 80 & 25 & 0 & 0 \\
\hline 18 & 280 & 15 & 7 & 3 \\
\hline 19 & 86 & 18,2 & 7,6 & 6 \\
\hline 20 & 150 & 53 & 22,3 & 0 \\
\hline 21 & 115 & 16,3 & 10,3 & 0 \\
\hline 22 & 63 & 12 & 0 & 0 \\
\hline 23 & 30 & 2,3 & 0,6 & 0 \\
\hline 24 & 120 & 0 & 0 & 0 \\
\hline 25 & 580 & 203 & 38 & 3,9 \\
\hline 26 & 240 & 30 & 5 & 0 \\
\hline 27 & 45 & 3,6 & 0 & 0 \\
\hline 28 & 42 & 6,4 & 6 & 0 \\
\hline 29 & 320 & 29 & 5 & 2 \\
\hline 30 & 400 & 24 & 22 & 22 \\
\hline 31 & 480 & 44 & 20 & 9,6 \\
\hline 32 & 30 & 16,4 & 7,6 & 0 \\
\hline 33 & 520 & 37 & 30 & 5,2 \\
\hline Média & 298,2 & 47,9 & 25,2 & 12,7 \\
\hline DP & 346,9 & 59,4 & 42,8 & 30 \\
\hline $\mathrm{P}$ & \multicolumn{2}{|c|}{0,0000} & & 0,0002 \\
\hline
\end{tabular}


Observou-se correlação positiva entre o volume inicial do cisto e seu volume residual, com coeficiente de correlação linear de Pearson $\boldsymbol{r}=0,7770$, com $p=0,0000$ (figura 12), demonstrando que quanto maior o cisto inicial, maior o cisto residual.

Figura 12: Gráfico ilustrando a correlação positiva entre volume inicial e residual do cisto.

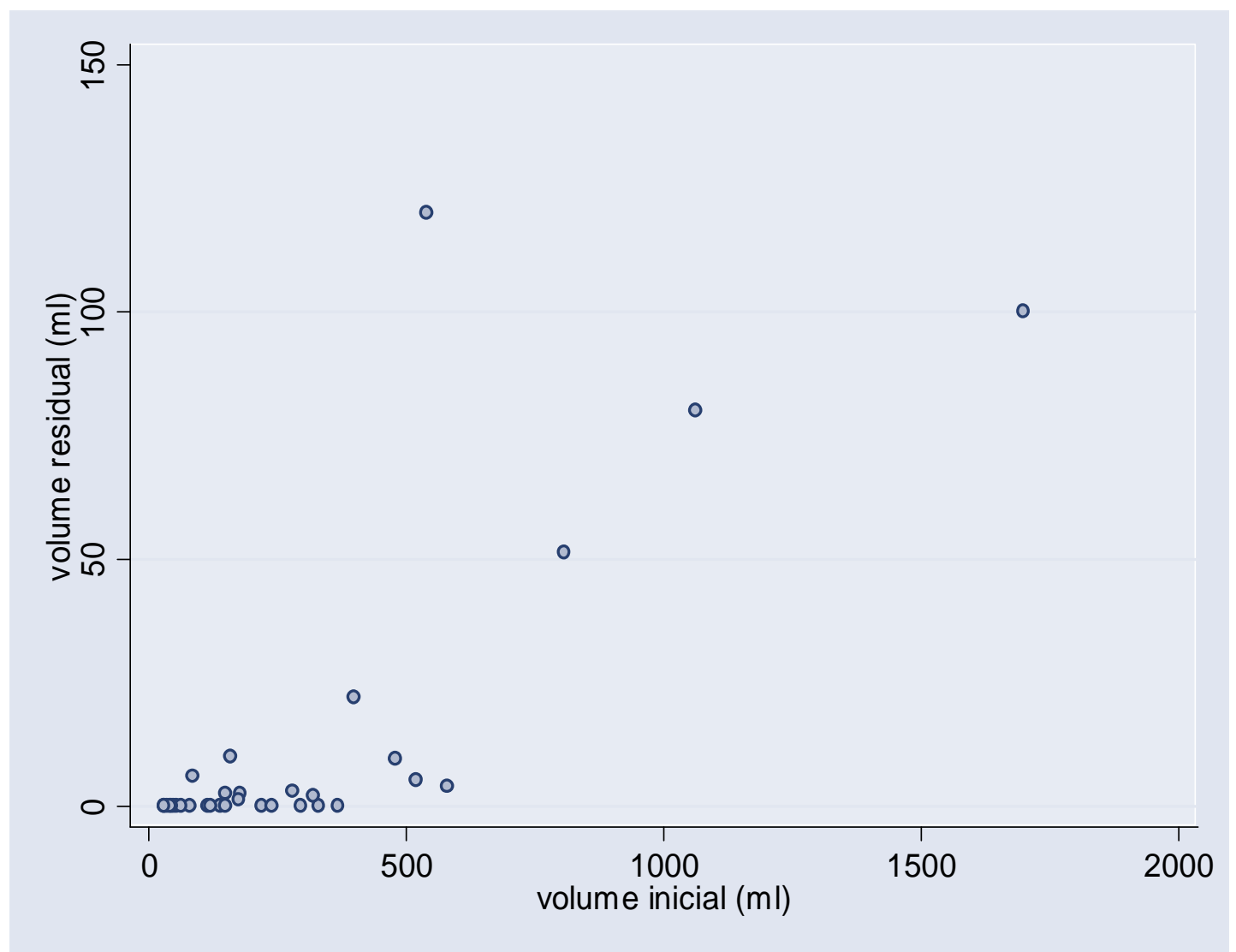


Trinta (91\%) pacientes apresentaram remissão completa dos sintomas e se consideraram curados após o seguimento de seis meses. Três $(9 \%)$ estavam sintomáticos neste período (casos 7,11 e 17). O paciente identificado no caso número 7 apresentava cisto residual de $120 \mathrm{ml}$; o caso 11, embora mantivesse sintomas, os considerou com intensidade muito menor, atribuindo-lhe o valor 2 em escala visual numérica quando comparado com o valor pré-tratamento de 6 e o caso 17 manteve a mesma intensidade de sintomas apesar do desaparecimento do cisto (tabela 7). 
Tabela 7: Comparação da dor antes e depois do tratamento do cisto renal simples através de escala visual numérica.

\begin{tabular}{|c|c|c|c|c|c|}
\hline \multirow[b]{2}{*}{ Caso } & \multicolumn{2}{|c|}{ Pré-tratamento } & \multicolumn{3}{|c|}{ Pós-tratamento } \\
\hline & Escala visual & intensidade & $\begin{array}{c}\text { Escala visual } \\
1 \text { mês }\end{array}$ & $\begin{array}{c}\text { Escala visual } \\
3 \text { meses }\end{array}$ & $\begin{array}{c}\text { Escala visual } \\
6 \text { meses }\end{array}$ \\
\hline 1 & 3 & fraca & 0 & 0 & 0 \\
\hline 2 & 6 & moderada & 1 & 1 & 0 \\
\hline 3 & 5 & moderada & 0 & 0 & 0 \\
\hline 4 & 5 & moderada & 0 & 0 & 0 \\
\hline 5 & 6 & moderada & 0 & 0 & 0 \\
\hline 6 & 5 & moderada & 0 & 0 & 0 \\
\hline 7 & 6 & moderada & 5 & 5 & 5 \\
\hline 8 & 5 & moderada & 0 & 0 & 0 \\
\hline 9 & 7 & forte & 2 & 0 & 0 \\
\hline 10 & 4 & moderada & 0 & 0 & 0 \\
\hline 11 & 6 & moderada & 2 & 2 & 2 \\
\hline 12 & 5 & moderada & 1 & 0 & 0 \\
\hline 13 & 4 & moderada & 0 & 0 & 0 \\
\hline 14 & 6 & forte & 2 & 1 & 0 \\
\hline 15 & 4 & moderada & 0 & 0 & 0 \\
\hline 16 & 4 & moderada & 2 & 0 & 0 \\
\hline 17 & 8 & forte & 7 & 7 & 7 \\
\hline 18 & 5 & moderada & 0 & 0 & 0 \\
\hline 19 & 4 & moderada & 0 & 0 & 0 \\
\hline 20 & 5 & moderada & 2 & 0 & 0 \\
\hline 21 & 6 & moderada & 0 & 0 & 0 \\
\hline 22 & 4 & fraca & 0 & 0 & 0 \\
\hline 23 & 4 & moderada & 0 & 0 & 0 \\
\hline 24 & 6 & forte & 0 & 0 & 0 \\
\hline 25 & 5 & moderada & 1 & 0 & 0 \\
\hline 26 & 6 & forte & 0 & 0 & 0 \\
\hline 28 & 5 & moderada & 0 & 0 & 0 \\
\hline 29 & 5 & moderada & 1 & 0 & 0 \\
\hline 30 & 6 & moderada & 0 & 0 & 0 \\
\hline 30 & 6 & moderada & 0 & 0 & 0 \\
\hline 31 & 5 & moderada & 0 & 0 & 0 \\
\hline 32 & 4 & moderada & 0 & 0 & 0 \\
\hline 33 & 6 & moderada & 0 & 0 & 0 \\
\hline
\end{tabular}


Discussão 


\section{Discussão}

A idéia de tratar o cisto renal simples de maneira pouco agressiva precedeu o aprimoramento dos métodos de imagem. Seu tratamento apenas com aspiração do conteúdo, técnica existente antes do surgimento da ultrasonografia, foi considerada ineficaz, uma vez que em aproximadamente $90 \%$ dos casos havia recidiva para volume próximo ao inicial ${ }^{16,83,51,109,28}$.

Para diminuir a recidiva do cisto após a punção esvaziadora, preconizou-se a injeção de substâncias no seu interior com o objetivo de gerar processo inflamatório e necrose do epitélio que o reveste e, com isso, atingir resultado melhor. Diversos agentes foram testados: iodo-povidona ${ }^{8,71}$, cloreto de sódio hipertônico ${ }^{76}$, betadina ${ }^{73}$, cola de fibrina ${ }^{77}$, minociclina ${ }^{75}$, sangue autólogo ${ }^{69}$, dióxido de carbono ${ }^{74}$, tetraciclina ${ }^{29}$ e etanol 9,13,80,54,82,10,110,75,84,85,1,86. Este tem sido o agente esclerosante mais utilizado pela facilidade de obtenção, manuseio, eficácia, segurança e metabolismo conhecido.

A escleroterapia em uma única sessão tem resultados piores se comparada ao procedimento realizado em múltiplas sessões ${ }^{9,13,1}$ ou com associação de drenagem contínua ${ }^{54}$, se o agente esclerosante for drenado após o procedimento $\left(57 \% \times 95 \%\right.$ de sucesso) ${ }^{9}$. Em nossa casuística os resultados obtidos em uma única sessão sem a retirada do esclerosante são semelhantes aos obtidos em múltiplas sessões pelos diversos autores 1,9,13,80,81,54,82,10,110,83,75,84,85,86. Tal fato pode ser atribuído à ação prolongada 
do etanol gerada por sua permanência na cavidade do cisto, necessária para atingir sua parede além do epitélio, fato inovador na técnica proposta neste estudo. A realização do procedimento em sessões múltiplas implica na colocação de cateter no interior do cisto e a sua permanência por mais de 24 horas para permitir a drenagem do líquido e instilação do agente esclerosante. Esse procedimento aumenta a morbidade e o custo da escleroterapia, sendo relatada quebra da ponta do cateter no interior do cisto 111.

O álcool etílico age rapidamente nas células do epitélio do cisto, coagulando-as. Tal efeito é observado com exposição de 1 a 3 minutos. No entanto, apenas penetra a cápsula do cisto após 4 a 12 horas ${ }^{28}$, o que explica a absorção lenta dessa substância, praticamente sem efeitos sistêmicos significativos. Esse fato deve estar também relacionado à maior taxa de sucesso obtida em nossa casuística, onde o agente é deixado no interior do cisto, podendo atuar também sobre sua cápsula.

O etanol, quando ingerido, é rapidamente absorvido pelas mucosas do estômago, intestino delgado e cólon. Diversos fatores interferem no ritmo de absorção, como presença de alimento no estômago, velocidade de trânsito intestinal, entre outros ${ }^{95}$. Embora o epitélio que reveste o cisto renal não tenha função absortiva, também ocorre absorção dessa substância, quando é injetada no seu interior. Entretanto, isso ocorre em ritmo mais lento, com o pico de absorção de uma a três horas após sua injeção ${ }^{96}$.

Noventa a $98 \%$ do etanol que entra no organismo por qualquer via é oxidado e a velocidade de oxidação é independente da concentração sérica. 
A oxidação dessa substância ocorre no fígado, iniciada pela desidrogenase alcoólica. O produto, acetaldeído, é convertido em acetil-CoA, que é oxidada no ciclo do ácido cítrico ou utilizado em reações anabólicas na síntese de colesterol, ácidos graxos e outros constituintes dos tecidos ${ }^{95}$. Apenas $2 \%$ não sofrem oxidação e são excretados pelos rins e pelos pulmões na forma original. Tal proporção pode chegar a $10 \%$ no caso de ingestão de doses altas. A velocidade média de metabolismo no adulto é de aproximadamente $120 \mathrm{mg} / \mathrm{kg}$ por hora, ou seja, $30 \mathrm{~g}$ a cada três horas. Sinais de intoxicação leve são observados em indivíduos com concentrações séricas entre $0,2 \mathrm{~g} / \mathrm{l}$ e 0,3 g/l. Com concentração sérica de $1,5 \mathrm{~g} / \mathrm{l}, 50 \%$ dos indivíduos estão bastante intoxicados e concentrações de $4 \mathrm{~g} / \mathrm{l}$ podem ser fatais ${ }^{95}$. A legislação americana para condução de veículos automotores considera concentrações acima de 1,0 g/l incapacitantes para a condução do veículo. A ingestão de $100 \mathrm{ml}$ de bebida destilada (uísque ou aguardente de cana) em jejum gera concentrações plasmática de etanol de 0,67 a 0,92 g/l. Após uma refeição mista, a mesma ingestão alcoólica gera concentrações séricas equivalentes à metade da obtida com sua ingestão em jejum.

A concentração observada 60 minutos após a injeção de $160 \mathrm{ml}$ desse agente esclerosante no cisto não ultrapassa $0,3 \mathrm{~g} / \mathrm{l}^{1,96}$, que é inferior à metade da obtida com a ingestão de $100 \mathrm{ml}$ de bebida destilada em jejum. Mesmo sem a retirada do etanol do interior do cisto, a absorção lenta do álcool e seu metabolismo contínuo explicam a ausência de intoxicação alcoólica grave observada em nossa casuística. Sinais de intoxicação leve são inespecíficos e podem ser confundidos com efeitos colaterais de 
medicação analgésica e sedativa administrada aos pacientes previamente ao procedimento e, por isso, não foram pesquisados.

Com o objetivo de evitar o tratamento de cistos que não sejam responsáveis pelos sintomas do paciente, foi proposta a punção esvaziadora do cisto sem sua esclerose como teste diagnóstico previamente à terapia definitiva ${ }^{14}$. Entretanto, a baixa morbidade associada à escleroterapia do cisto renal com a substância estudada e a baixa incidência de erro diagnóstico, observada em apenas um caso na nossa série (caso 17), não justificam esse procedimento.

Diversos autores propõem o uso de contraste iodado no interior do cisto para descartar comunicação com a via excretora ${ }^{9,82,8}$. No entanto, o diagnóstico seguro de cisto renal simples sem comunicação com a via excretora pode ser estabelecido com a ultra-sonografia e outros métodos de imagem quando necessários, realizados previamente ao procedimento. A fim de evitar o extravasamento do etanol durante sua injeção no cisto, preconizamos o uso concomitante da ultra-sonografia com o recurso do Doppler colorido, que possibilita a monitorização em tempo real da sua injeção.

Observamos a redução progressiva do volume do cisto durante 0 decorrer dos seis primeiros meses após o procedimento. Portanto, a presença de cisto residual nesse período não deve ser interpretada como falha do método. Após esse prazo, se não houver redução significativa do volume do cisto e se persistirem os sintomas, como ocorrido no caso 7 , o procedimento pode ser realizado novamente (figura 13). 
Figura 13: Algoritmo para o tratamento do cisto renal simples sintomático.

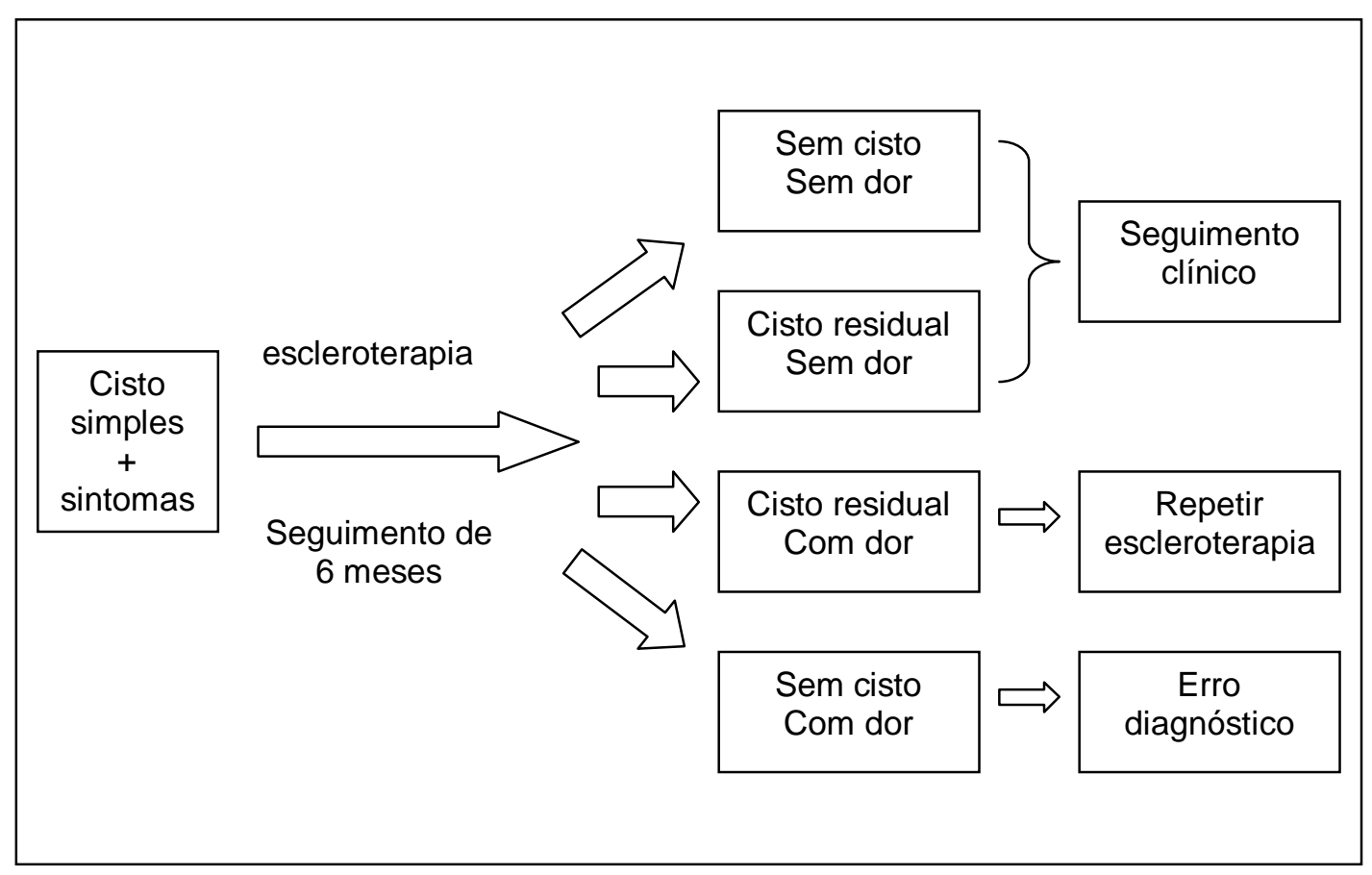

A regressão lenta do tamanho do cisto, podendo durar mais de seis meses, sugere a presença de processo inflamatório local, que acompanha a redução do cisto, o que pode, em alguns casos, explicar a melhora mais lenta dos sintomas relacionados a essa lesão, como observado no caso 11.

Índices de falha na esclerose do cisto renal simples são superiores nos cistos maiores ${ }^{28}$. Na casuística apresentada observamos maior freqüência de cistos residuais nos cistos maiores, principalmente nos que apresentavam volume inicial superior a $600 \mathrm{ml}$. No entanto, observa-se que a remissão dos sintomas não está obrigatoriamente associada ao desaparecimento do cisto, podendo ser sua redução de volume suficiente para a completa melhora dos sintomas. E, havendo desaparecimento dos 
sintomas, o cisto residual não requer tratamento adicional, visto que o tratamento do cisto renal foi motivado pela presença de sintomas, independente de seu tamanho. 
Conclusões 


\section{Conclusões}

1 - O tratamento do cisto renal simples por aspiração percutânea e injeção permanente de etanol absoluto em sessão única é segura, eficaz e minimamente invasiva.

2 - A redução do volume do cisto é gradual e o desaparecimento pode demorar até 6 meses.

4 - Existe correlação positiva entre o volume inicial e o residual do cisto.

5 - A redução parcial do volume do cisto renal pode ser suficiente para 0 desaparecimento dos sintomas. 
Referências 


\section{Referências}

1. Paananen I, Hellstrom P, Leinonen S, Merikanto J, Perala J,

Paivansalo M, Lukkarinen O. Treatment of renal cysts with singlesession percutaneous drainage and ethanol sclerotherapy: longterm outcome. Urology. 2001; 57: 30-3.

2. Terada N, Ichioka K, Matsuta Y, Okubo K, Yoshimura K, Arai Y. The natural history of simple renal cysts. J Urol. 2002; 167: 21-3.

3. Kissane JM. The morphology of renal cystic disease. Perspect Nephrol Hypertens. 1976; 4: 31-63.

4. Smith $\mathrm{EH}$, Bennett $\mathrm{AH}$. The usefulness of ultrasound in the evaluation of renal masses in adults. J Urol. 1975; 113: 525-9.

5. Lang EK. Renal cyst puncture studies. Urol Clin North Am. 1987; 14: 91-102.

6. Gordon RL, Pollack HM, Popky GL, Duckett JW, Jr. Simple serous cysts of the kidney in children. Radiology. 1979; 131: 357-61.

7. Laucks SP, Jr., McLachlan MS. Aging and simple cysts of the kidney. Br J Radiol. 1981; 54: 12-4. 
8. Phelan M, Zajko A, Hrebinko RL. Preliminary results of percutaneous treatment of renal cysts with povidone-iodine sclerosis. Urology. 1999; 53: 816-7.

9. Chung $\mathrm{BH}$, Kim JH, Hong $\mathrm{CH}$, Yang SC, Lee MS. Comparison of single and multiple sessions of percutaneous sclerotherapy for simple renal cyst. BJU Int. 2000; 85: 626-7.

10. Aboutaieb R, Joual A, Ousehal A, el Mrini M, Benjelloun S.

[Percutaneous alcoholization of simple serous cysts of the kidney]. Ann Urol (Paris). 1995; 29: 280-3.

11. Brown B, Sharifi R, Lee M. Ethanolamine sclerotherapy of a renal cyst. J Urol. 1995; 153: 385-6.

12. Denstedt JD. Taking action when simple renal cysts cause symptoms. Contemp Urol. 1994; 6: 46-52.

13. Fontana D, Porpiglia F, Morra I, Destefanis P. Treatment of simple renal cysts by percutaneous drainage with three repeated alcohol injection. Urology. 1999; 53: 904-7.

14. Okeke AA, Mitchelmore AE, Keeley FX, Timoney AG. A comparison of aspiration and sclerotherapy with laparoscopic de-roofing in the management of symptomatic simple renal cysts. BJU Int. 2003; 92: 610-3. 
15. Lezrek M, Fassi-Fehri H, Badet L, Marechal JM, Martin X. Remission of erythrocytosis and hypertension after treatment of a giant renal cyst. Urology. 2002; 60: 164.

16. Wolf JS, Jr. Evaluation and management of solid and cystic renal masses. J Urol. 1998; 159: 1120-33.

17. Hoard TD, O'Brien DP, III. Simple renal cyst and high renin hypertension cured by cyst decompression. J Urol. 1976; 115: 3267.

18. Stanisic TH, Babcock JR, Grayhack JT. Morbidity and mortality of renal exploration for cyst. Surg Gynecol Obstet. 1977; 145: 733-6.

19. Bellman GC, Yamaguchi R, Kaswick J. Laparoscopic evaluation of indeterminate renal cysts. Urology. 1995; 45: 1066-70.

20. Morgan C, Jr., Rader D. Laparoscopic unroofing of a renal cyst. J Urol. 1992; 148: 1835-6.

21. Eden CG, Adamson A, Jeer PJ, Smith AS, Coptcoat MJ.

Retroperitoneoscopic renal cystectomy--an unusual pitfall. $\mathrm{Br} \mathrm{J}$ Urol. 1995; 75: 674-5.

22. Hemal AK, Aron M, Gupta NP, Seth A, Wadhwa SN. The role of retroperitoneoscopy in the management of renal and adrenal pathology. BJU Int. 1999; 83: 929-36. 
23. Wong HY, Griffith DP. Retroperitoneal endoscopic excision of renal cysts. Br J Urol. 1994; 74: 674-5.

24. Yagisawa T, Ito F, Shimizu T, Toma H, Yamagata K, Ikeda M. Retroperitoneoscopic unroofing of a renal cyst under epidural anesthesia. J Endourol. 2001; 15: 607-9.

25. Kang $Y$, Noble $C$, Gupta M. Percutaneous resection of renal cysts. $J$ Endourol. 2001; 15: 735-8.

26. Plas EG, Hubner WA. Percutaneous resection of renal cysts: a longterm followup. J Urol. 1993; 149: 703-5.

27. Weichert-Jacobsen K, Loch T, Kuppers F, Stockle M. Clinical experience with percutaneous renal cyst resection. BJU Int. 1999; 84: $164-6$.

28. Bean WJ. Renal cysts: treatment with alcohol. Radiology. 1981; 138: 329-31.

29. Liatsikos EN, Siablis D, Karnabatidis D, Kalogeropooulou C, Triadopoulos A, Petsas T, Tsota I, Ravazoula P, Barbalias GA. Percutaneous treatment of large symptomatic renal cysts. $J$ Endourol. 2000; 14: 257-61. 
30. Guazzoni G, Montorsi F, Bergamaschi F, Consonni P, Bellinzoni P, Centemero A, Rigatti P. Laparoscopic unroofing of simple renal cysts. Urology. 1994; 43: 154-9.

31. Limb J, Santiago L, Kaswick J, Bellman GC. Laparoscopic evaluation of indeterminate renal cysts: long-term follow-up. J Endourol. 2002; 16: 79-82.

32. McNally ML, Erturk E, Oleyourryk G, Schoeniger L. Laparoscopic cyst decortication using the harmonic scalpel for symptomatic autosomal dominant polycystic kidney disease. J Endourol. 2001; 15: 597-9.

33. Nieh PT, Bihrle W, III. Laparoscopic marsupialization of massive renal cyst. J Urol. 1993; 150: 171-3.

34. Roberts WW, Bluebond-Langner R, Boyle KE, Jarrett TW, Kavoussi LR. Laparoscopic ablation of symptomatic parenchymal and peripelvic renal cysts. Urology. 2001; 58: 165-9.

35. Rubenstein SC, Hulbert JC, Pharand D, Schuessler WW, Vancaillie TG, Kavoussi LR. Laparoscopic ablation of symptomatic renal cysts. J Urol. 1993; 150: 1103-6.

36. Stoller ML, Irby PB, III, Osman M, Carroll PR. Laparoscopic marsupialization of a simple renal cyst. J Urol. 1993; 150: 1486-8. 
37. Valdivia Uria JG, Abril BG, Monzon AF, Lanchares SE. [Laparoscopic ablation of renal cysts]. Arch Esp Urol. 1994; 47: 246-52.

38. Devine CJ, Jr., Buttarazzi PJ, Devine PC, Fiveash JG, Jr., Poutasse EF. Aspiration or exploration to confirm diagnoses of renal masses. JAMA. 1968; 204: 758-62.

39. Fortuno RF, Dubocq F. The morbidity of a renal exploration. Bol Asoc Med P R. 1971; 63: 178-80.

40. Kauder DH, DeWolf WC. Diagnostic surgical exploration for renal masses. Minn Med. 1976; 59: 13-4.

41. Kropp KA, Grayhack JT, Wendel RM, Dahl DS. Morbidity and mortality of renal exploration for cyst. Surg Gynecol Obstet. 1967; 125: 8036.

42. Marshall FF. The role of selective exploration in ambiguous renal cystic lesions. Urol Clin North Am. 1980; 7: 689-95.

43. Zelch J, Lalli AF, Stewart BH, Daughtry JD. Complications of renal cyst exploration versus renal mass aspiration. Urology. 1976; 7: 244-7.

44. Wehle MJ, Grabstald H. Contraindications to needle aspiration of a solid renal mass: tumor dissemination by renal needle aspiration. $J$ Urol. 1986; 136: 446-8. 
45. Ambrose SS, Lewis EL, O'Brien DP, III, Walton KN, Ross JR. Unsuspected renal tumors associated with renal cysts. J Urol. 1977; 117: 704-7.

46. Evans J. The accuracy of diagnostic radiology. Arteriography and nephrotomography. JAMA. 1968; 204: 223-6.

47. Kaiser TF, Hodson JM, Seibel RE, Albee RD, Farrow FC, McMahon JJ. Evaluation of asymptomatic renal masses by selective renal angiography and percutaneous needle puncture: a preliminary report. J Urol. 1967; 98: 436-43.

48. Witherington R, Rinker JR. Percutaneous needle puncture in the diagnosis of renal cysts. J Urol. 1966; 95: 733-7.

49. Lang EK. Roentgenographic assessment of asymptomatic renal lesions. An analysis of the confidence level of diagnoses established by sequential roentgenographic investigation. Radiology. 1973; 109: 257-69.

50. Lang EK. The differential diagnosis of renal cysts and tumors. Cyst puncture, aspiration, and analysis of cyst content for fat as diagnostic criteria for renal cysts. Radiology. 1966; 87: 883-8. 
51. Raskin MM, Poole DO, Roen SA, Viamonte M, Jr. Percutaneous management of renal cysts: results of a four-year study. Radiology. 1975; 115: 551-3.

52. Balfe DM, McClennan BL, Stanley RJ, Weyman PJ, Sagel SS. Evaluation of renal masses considered indeterminate on computed tomography. Radiology. 1982; 142: 421-8.

53. Raskin MM, Cunningham JB. Evaluation of renal masses by ultrasound and computed tomography: a preliminary study. $J$ Comput Tomogr. 1978; 2: 343-7.

54. Pfister C, Sibert L, Thoumas D, Massy J, Grise P. [The role of percutaneous puncture alcohol sclerotherapy in the treatment of symptomatic kidney cysts]. Prog Urol. 1996; 6: 543-7.

55. Bosniak MA. The current radiological approach to renal cysts. Radiology. 1986; 158: 1-10.

56. Bosniak MA. The use of the Bosniak classification system for renal cysts and cystic tumors. J Urol. 1997; 157: 1852-3.

57. Bosniak MA. Cystic renal masses: a reevaluation of the usefullness of the Bosniak Classification System. Acad Radiol. 1996; 3: 981-4. 
58. Israel GM, Bosniak MA. Follow-up CT of moderately complex cystic lesions of the kidney (Bosniak category IIF). AJR Am J Roentgenol. 2003; 181: 627-33.

59. Israel GM, Bosniak MA. Calcification in cystic renal masses: is it important in diagnosis? Radiology. 2003; 226: 47-52.

60. Spahn M, Portillo FJ, Michel MS, Siegsmund M, Gaa J, Alken P, Junemann KP. Color Duplex sonography vs. computed tomography: accuracy in the preoperative evaluation of renal cell carcinoma. Eur Urol. 2001; 40: 337-42.

61. Kreft BP, Muller-Miny H, Sommer T, Steudel A, Vahlensieck M, Novak D, Muller BG, Schild HH. Diagnostic value of MR imaging in comparison to $\mathrm{CT}$ in the detection and differential diagnosis of renal masses: ROC analysis. Eur Radiol. 1997; 7: 542-7.

62. Lang EK. Coexistence of cyst and tumor in the same kidney. Radiology. 1971; 101: 7-16.

63. Clayman RV, Williams RD, Fraley EE. The pursuit of the renal mass. N Engl J Med. 1979; 300: 72-4.

64. Pollack HM, Goldberg BB, Bogash M. Changing concepts in the diagnosis and management of renal cysts. J Urol. 1974; 111: 3269. 
65. Holzer DH, Muller JH, Schulz R, Neuser D. [Results of percutaneous kidney cyst sclerosing]. Z Urol Nephrol. 1981; 74: 213-6.

66. Raskin MM, Roen SA, Viamonte M, Jr. Effect of intracystic pantopaque on renal cysts. $J$ Urol. 1975; 114: 678-9.

67. Raskin MM, Roen SA, Serafini AN. Renal cyst puncture: combined fluoroscopic and ultrasonic technique. Radiology. 1974; 113: 4257.

68. Raskin MM, Roen SA. Determination of renal cyst volume. Radiology. 1973; 107: 704-5.

69. Wernecke K, Heckemann R, Rehwald U. [Therapeutic results of ultrasonically-guided kidney cyst punctures]. ROFO Fortschr Geb Rontgenstr Nuklearmed. 1985; 143: 553-6.

70. Schramek P, Hubner W, Dunser E, Umek H, Porpaczy P. [Ultrasound controlled kidney cyst puncture: significance for diagnosis and therapy]. Ultraschall Med. 1988; 9: 169-71.

71. Sanz CS, Boronat TF, Martinez Jabaloyas JM, Jimenez Cruz JF. [Percutaneous treatment of renal cysts with iodinated povidone injection. Long-term clinical course]. Actas Urol Esp. 1997; 21: 6627. 
72. Shinoda I, Ishihara S, Takeuchi T, Takahashi Y, Yamaha M, Kanematsu M, Kuriyama M, Ban Y, Kawada Y, Yamada S, . [Ultrasound-guided puncture for renal cyst and instillation of povidone iodine]. Hinyokika Kiyo. 1988; 34: 1741-5.

73. Ibnatya A, Tazi K, Koutani A, Khader K, El Mamoun M, Hachimi M, Lakrissa A. [Sclerotherapy with Betadine for simple cysts of the kidney. Apropos of 7 cases]. J Urol (Paris). 1995; 101: 237-9.

74. Tabata S, Ozono S, Otani T, Saka T, Hirao Y, Okajima E, Tanaka Y, Yamada K, Hirohashi S, Sakaguchi H. [Percutaneous renal cyst puncture with CO2 instillation therapy]. Hinyokika Kiyo. 1994; 40: 475-8.

75. Nishimura K, Tsujimura A, Matsumiya K, Oka T, Takaha M. [Clinical experience of percutaneous renal cyst puncture in recent six years]. Hinyokika Kiyo. 1993; 39: 121-5.

76. Kabaalioglu A, Apaydin A, Ozkaynak C, Melikoglu M, Sindel T, Luleci E. Percutaneous sclerotherapy of a symptomatic simple renal cyst in a child: observation of membrane detachment sign. Eur Radiol. 1996; 6: 872-4.

77. Santoriello A, Petraroia F, Vanore A, Carnevale M, Ascione A, Canonico S. [Ultrasonically guided percutaneous treatment of renal 
cysts using ethanol and human fibrin glue (tissucol)]. Minerva Chir. 1994; 49: 343-8.

78. Zou SZ, Fan WN, He XH. Percutaneous ultrasound-guided injection of sodium morrhuate in the treatment of cystic renal masses. $\mathrm{Br} \mathrm{J}$ Urol. 1991; 68: 441-2.

79. Holmberg G, Hietala SO. Treatment of simple renal cysts by percutaneous puncture and instillation of bismuth-phosphate. Scand J Urol Nephrol. 1989; 23: 207-12.

80. Porpiglia F, Morra I, Rocca A, Fontana D. [Treatment of a solitary renal cyst using percutaneous drainage and repeat alcoholization]. Arch Ital Urol Androl. 1996; 68: 197-9.

81. Porpiglia F, Tarabuzzi R, Morra I, Fontana D. [Treatment of voluminous renal cysts with drainage and repeated percutaneous administration of alcohol. Our experience]. Arch Ital Urol Androl. 1994; 66: 215-7.

82. el Diasty TA, Shokeir AA, Tawfeek HA, Mahmoud NA, Nabeeh A, Ghoneim MA. Ethanol sclerotherapy for symptomatic simple renal cysts. J Endourol. 1995; 9: 273-6.

83. Zama S. [Percutaneous renal cyst puncture and ethanol instillation]. Hinyokika Kiyo. 1994; 40: 9-13. 
84. Bianchi G, Cavalleri S, D'Amico A, Tallarigo C, Malossini G, Beltrami P. [Treatment of renal cysts by percutaneous drainage and alcoholization. Our experience]. J Urol (Paris). 1990; 96: 185-8.

85. Ozgur S, Cetin S, llker Y. Percutaneous renal cyst aspiration and treatment with alcohol. Int Urol Nephrol. 1988; 20: 481-4.

86. Garcia NF, Rey RR, Mateo CL, Perez MP, Asorey FA, Ruiz DE. [Symptomatic simple cyst of the kidney. Treatment using punctureaspiration and sclerosis with 95\% ethanol]. Arch Esp Urol. 1990; 43: 269-72.

87. De Dominicis C, Ciccariello M, Peris F, Di Crosta G, Sciobica F, Zuccala A, lori F. Percutaneous sclerotization of simple renal cysts with $95 \%$ ethanol followed by $24-48 \mathrm{~h}$ drainage with nephrostomy tube. Urol Int. 2001; 66: 18-21.

88. Lohela P. Ultrasound-guided drainages and sclerotherapy. Eur Radiol. 2002; 12: 288-95.

89. Saracino GA, Battaglia M, Martino D, de Ceglie G, Carrieri G, Ditonno P, Martino P, Selvaggi FP. [Echo-guided percutaneous treatment of renal cysts: aspiration vs continuous 24-hour drainage]. Arch Ital Urol Androl. 1996; 68: 215-6. 
90. Veltri A, Biselli S, Farinet S, Mancini A. [Ultrasonography-guided alcohol injection in simple renal cysts. Long-term results]. Radiol Med (Torino). 1993; 86: 870-5.

91. Ohkawa M, Tokunaga S, Orito M, Shimamura M, Hirano S, Okasho A, Kosaka S. Percutaneous injection sclerotherapy with minocycline hydrochloride for simple renal cysts. Int Urol Nephrol. 1993; 25: 3743.

92. Nishikawa $Y$, Suzuki $H$, Suzuki $F$, Inomiya $H$, Ishibiki $Y$, Kotake $T$, Yamaguch K, Ito H. [Percutaneous renal cyst puncture and ethanol instillation]. Nippon Hinyokika Gakkai Zasshi. 1992; 83: 1448-51.

93. Lindemann IP, Zimmermann HB, Guddat HM, Dieterich WR. [Kidney cyst puncture for diagnosis and therapy]. Z Urol Nephrol. 1979; 72: 97-106.

94. Rehman J, Landman J, Sundaram C, Clayman RV. Tissue chemoablation. J Endourol. 2003; 17: 647-57.

95. Fleming M, Mihic F J, Harris R A. Ethanol. In: Hardman J G, Limbird L E, Goodman Gilman A. The pharmacological basis of therapeutics. 10th edition. New York: Mc Graw Hill; 2001, 429-45.

96. Kawamura J, Hiura M, Ueda M, Higashi Y, Yoshida O, Kuwahara C, Ueda M. [Ultrasound-guided renal cyst puncture and 95\% ethanol 
injection. Part 1: Estimation of ethanol levels in the blood and urine following 95\% ethanol injection]. Hinyokika Kiyo. 1984; 30: 287-94.

97. Bartolozzi C, Lencioni R, Ricci P, Paolicchi A, Rossi P, Passariello R. Hepatocellular carcinoma treatment with percutaneous ethanol injection: evaluation with contrast-enhanced color Doppler US. Radiology. 1998; 209: 387-93.

98. Talwar GL, Pande SK. Injection treatment of enlarged prostate. Br J Surg. 1966; 53: 421-7.

99. Littrup PJ, Lee F, Borlaza GS, Sacknoff EJ, Torp-Pedersen S, Gray JM. Percutaneous ablation of canine prostate using transrectal ultrasound guidance. Absolute ethanol and Nd:YAG laser. Invest Radiol. 1988; 23: 734-9.

100. Uflacker R, Paolini RM, Nobrega M. Ablation of tumor and inflammatory tissue with absolute ethanol. Acta Radiol Diagn (Stockh). 1986; 27: 131-8.

101. Livraghi T, Paracchi A, Ferrari C, Reschini E, Macchi RM, Bonifacino A. Treatment of autonomous thyroid nodules with percutaneous ethanol injection: 4-year experience. Radiology. 1994; 190: 529-33.

102. Solbiati L, Giangrande A, De Pra L, Bellotti E, Cantu P, Ravetto C. Percutaneous ethanol injection of parathyroid tumors under US 
guidance: treatment for secondary hyperparathyroidism. Radiology. 1985; 155: 607-10.

103. Hata M, Nakajima F, Takao M, Odajima K, leda K, Fujioka T, Nakamura H. [Endoscopic ethanol injection treatment for bladder cancer]. Hinyokika Kiyo. 1987; 33: 1794-9.

104. Yamamoto S, Miyake I, Takatori K, Ohmoto K, Mitsui Y, Shimabara M. [Percutaneous ethanol injection for unresectable pancreatic cancer-report of two cases]. Gan To Kagaku Ryoho. 1998; 25: 1969-71.

105. Masaki Y, Yamamoto M, Nishimura H, Gomibuchi M, Tanaka S. [Ethanol injection therapy to the lung cancer]. Kyobu Geka. 1997; 50: 384-8.

106. Turk DC, Okifuji A. Pain terms and taxonomies of pain. In: Loeser J D, Butler SH, Chapman CR, Turk DC. Bonica's mangement of pain. 3rd edition. Philadelphia: Lippincott Williams \& Wilkins; 17-9.

107. Coll AM, Ameen JR, Moseley LG. Reported pain after day surgery: a critical literature review. J Adv Nurs. 2004; 46: 53-65.

108. Chapman CR, Syrjala KL. Measurement of pain: approaches to measuring pain. In: Loeser JD, Butler SH, Chapman CR, Turk DC. 
Bonica's management of pain. 3rd edition. Philadelphia: Lippincott Williams \& Wilkins; 310-4.

109. Stevenson JJ, Sherwood T. Conservative management of renal masses. Br J Urol. 1971; 43: 646-7.

110. Furuta H, Nakada T, Akiya T, Ishikawa N, Satomi S, Sakamoto M, Kohno T, Kazama T, Umeda K, Sasagawa I, . [Renal cyst puncture under ultrasound guidance: complications of ethanol injection]. Hinyokika Kiyo. 1988; 34: 1575-8.

111. Kawamura J, Hiura M, Kuo YJ, Hatayama T, Tobisu K, Kita Y, Terai A, Ogawa O, Okamura Y, Ohishi K, . [Ultrasound-guided renal cyst puncture and 95\% ethanol instillation. Part 2: Morphological and functional alterations]. Hinyokika Kiyo. 1984; 30: 589-98. 